\title{
EXPERIMENTAL STUDY OF HORIZONTAL TWO- AND THREE-PHASE FLOW CHARACTERISTICS AT LOW TO MEDIUM LIQUID LOADING CONDITIONS
}

\author{
Joseph Xavier Francisco Ribeiro a, b, c, Ruiquan Liao a, b, Aliyu M. Aliyu ${ }^{\text {d }}$, Wei Luo ${ }^{\mathrm{a}, \mathrm{b}}$ Zilong Liua,b \\ a. Petroleum Engineering College, Yangtze University, 430100 Wuhan Hubei, China \\ b. Laboratory of Multiphase Flow, Gas Lift Innovation Centre, China National Petroleum \\ Corporation \\ c. Kumasi Technical University, P. O. Box 854, Kumasi, Ghana \\ d. Faculty of Engineering, University of Nottingham, NG7 2RD, United Kingdom.
}

Joseph X. F. Ribeiro (Corresponding author), Yangtze University, Wuhan Campus No. 111, Caidian District, Wuhan City Hubei Province, China, zip code 430100, joxaro@yahoo.com, +233244476160; Ruiquan Liao, 1036792057@qq.com ; Aliyu M. Aliyu, ali.aliyu@nottingham.ac.uk ; Wei Luo, luoruichang@163.com; Liu Zilong,zilongliu@yahoo.com

Keywords: three-phase flow, stratified flow, low liquid loading, liquid holdup, pressure drop

\begin{abstract}
An experimental study is conducted using a $0.075-\mathrm{m}$ ID pipe to investigate characteristics of two- and three-phase stratified flow in a horizontal pipeline. Experiments are conducted under low to medium liquid loading conditions which is common in wet-gas and long transportation pipelines. The flow characteristics investigated include flow pattern, liquid holdup and pressure drop. The experimental range covers superficial gas Reynolds numbers from 6314 to 200734, superficial liquid Reynolds numbers from 160 to 4391 and water-cut values from 0 to 90\%. Differential pressure transducers, quick closing valves and a high-speed camera are utilized to obtain the relevant data and the trends investigated. The observed flow patterns are stratified smooth, stratified wavy and stratified-annular flow. The transitions between flow patterns vary as a function of water-cut. The effect of water-cut on liquid holdup and pressure drop were relatively negligible especially at low water-cut conditions and the fine mixing of the oil-water mixture may be partially responsible for this. As a result, with the exception of flow pattern transitions, the performances of classical two-phase flow models (for the prediction of liquid holdup and pressure drop) appear unaffected when applied to air-oil-water 3-phase flows especially at high water-cuts.
\end{abstract}

\section{INTRODUCTION}

\subsection{Background}

Gas-liquid stratified flow at low liquid loading conditions is often encountered in numerous industrial applications involving horizontal pipelines [1, 2]. Preference for this flow regime in, for instance, long distance transfer pipelines transporting steam-water as well as natural gas-oil mixtures, provide the thrust for continued research for improved equipment design as well as optimal production. Stratified 
Published in Heat and Mass Transfer, DOI: https://doi.org/10.1007/s00231-019-02616-y

flow also offers the advantage of lower pressure drops than slug flow for example and, in addition, remains free from the challenges of intermittent behaviour of the latter [3].

Low liquid loading refers to a condition in a pipeline where the liquid volumetric flow rate is considerably lower than the gas volumetric flow rate. This condition is very common in wet gas transport pipelines [4, 5] where gas condensation can occur at certain conditions of temperature and pressure. The small quantity of liquid can be transported either as liquid film on the pipe wall at low gas flows or in the form of dispersed droplets at high gas velocities. Droplets formed are ejected into the gas phase due to the shear at the gas-liquid interface [6] and can travel at high velocities compared to the liquid velocity inside the film. Thus, they play a critical role in liquid transportation. Furthermore, it is recognized that droplet acceleration in the gas space results in a higher pressure drop in the system. Even though the amount of liquid can be extremely small inside low liquid loading systems, its impact on the pressure drop and further flow assurance challenges including hydrate formation and top-of-line corrosion can be significant. Additionally, gas transportation flow facilities and collection systems are designed using certain low liquid loading flow models implemented into commercial software. The reliability of the system design is therefore directly affected by the accuracy of these flow models [7].

Simultaneous flow of water with oil and gas is common in production pipelines in the petroleum industry. In many cases, the water fraction in the liquid phase can be in excess of $90 \%$ [8-10]. This is attributable to a number of reasons including formation water flow to the well because the oil field is mature, water injection into the reservoir to enhance production as part of enhanced oil recovery processes $[11,12]$ or to maintain pressure at the latter stage of production [13]. This may influence the afore-mentioned flow characteristics [14].

Considering the complex nature of gas-water-oil flows, a three-phase flow system can be analyzed as a pseudo two-phase gas-liquid flow system with an effective viscosity and average properties determined for the liquid phase [15-18]. The prime aim of this study is to investigate the main flow characteristics: flow pattern, liquid holdup and pressure drop in a three-phase system. A secondary aim of this study seeks to validate the predictions of popular models existing in literature including Beggs and Brill (1973) [19], Lockhart and Martinelli (1949) [20], Mukherjee and Brill [21, 22], Xiao et al. [23] and the TUFFP model of Zhang et al. [24] using the experimental results. In order to assess the efficacy of these published models (developed for traditional 2-phase flows), the current experimental data is treated as a pseudo 2-phase system. We show in the results section that this approach is acceptable, as the pressure 
Published in Heat and Mass Transfer, DOI: https://doi.org/10.1007/s00231-019-02616-y

drop and holdup data compared with predictions by several models is acceptable. This is especially so for the models of Mukherjee and Brill, Xiao et al. as well as that of Lockhart and Martinelli.

\subsection{Previous Works}

A more comprehensive understanding of the low liquid loading pipe flows is essential to develop more physical and accurate flow prediction models [4] and in the design of wet gas pipelines and downstream facilities of deep-water gas fields [5]. Currently, laboratory experiments offer the most suitable way to carry out carefully designed flow experiments in order to observe and understand the underlying processes. The most important parameters which can provide insight into this problem and can also be extracted through laboratory experiments under low liquid loading flows include pressure drop, liquid holdup, entrained liquid fraction, film thickness circumferential distribution, wetted fraction, wave characteristics (amplitude and frequency), velocity fields inside the gas phase and liquid film (obtained by employing popular techniques including particle image velocimetry (PIV) [25-29] and high speed planar laser-induced fluorescence [30, 31]), wall shear stress distribution (acquired using hot film anemometry [32]), and droplet velocity and size distributions. Efficient design and operation require sound knowledge of the behaviour and reliable estimates of these multiphase flow characteristics in pipes [10, 33-35].

Several authors have reported significant findings from studies of two- $[19,21,36-39]$ and three-phase flows [16, 40-44]. Further, some studies have been conducted in other research centres to analyse low liquid loading flow for two-phase [1, 4, 5, 45, 46] and three-phase [14], [45], [47]- [49]. Comparatively, few experimental studies under these conditions have been reported for three-phase flows. Dong et al. [47] modified the 6-in ID facility of Fan et al. [45] to conduct low liquid loading three-phase flow experiments. Water, air, and oil (with the viscosity of $13 \mathrm{mPa} s$ ) were the flowing fluids. The distribution of oil and water in liquid phase for different flowing conditions was observed and categorized. In addition, a model comparison was provided for flow characteristics. Gawas [48] employed the same 6-in ID facility of Dong et al. [47] to investigate the droplet characteristics of three-phase low liquid loading flow. He conducted his experiments using an oil with viscosity of $1.3 \mathrm{mPa} s$ for different values of water-cut and developed correlations for entrainment of liquid droplets in gas phase for two- and three-phase flows. He also analyzed the droplet size distribution and developed a correlation for interfacial wave celerity. A summary of these studies is presented in Gawas [48]. Karami et al. [14] utilized the facility of Gawas [48] with the main objective of investigating targeted flow parameters including liquid holdup, water holdup, wave pattern, and pressure gradient under three-phase low liquid loading flow conditions to improve understanding of the flow phenomena. The experimental results for 
Published in Heat and Mass Transfer, DOI: https://doi.org/10.1007/s00231-019-02616-y

different flow characteristics were analyzed and evaluated. In addition, commonly used models were evaluated using the acquired experimental data. Quite recently, Karami et al. [49] has reported a modelling study of three-phase low liquid loading flow in horizontal pipes and also investigated droplet entrainment in three-phase flow at low liquid loading conditions [49].

From the experimental studies reviewed, the liquid phases are reported to be introduced separately into the test section. Cases where the liquid consists of a homogeneous mixture of oil and water have not been reported. In the current study, two- and three-phase experiments are conducted at low liquid loading conditions. Air and oil are utilized for the two-phase experiments while for the three-phase experiment, a homogenous mixture of oil and water as the liquid phase and air constituting the gas phase are employed. The prime aim of this study is to investigate the main flow characteristics: flow pattern, liquid holdup and pressure drop.

\subsubsection{Flow Pattern Prediction}

Flow pattern correlations differ for all authors. Beggs and Brill [19] as well as Mukherjee and Brill [22] opted for empirical models while Xiao et al. [23] as well as Zhang et al. [24] utilized theoretical approaches. Xiao et al. [23] adopted the model of Taitel and Dukler [50] with minor modifications. Based on the anticipation of wave development due to either the interfacial shear or as a result of instability due to the action of gravity, Taitel and Dukler [50] proposed the following criterion based on the theory of Jeffery to account for waves induced by the "wind effect":

$v_{g}>\left[\frac{4 \mu_{l}\left(\rho_{l}-\rho_{g}\right) g \cos (\alpha)}{s \rho_{l} \rho_{g} v_{l}}\right]^{1 / 2} v_{g}>\left[\frac{4 \mu_{l}\left(\rho_{l}-\rho_{g}\right) g \cos (\alpha)}{s \rho_{l} \rho_{g} v_{l}}\right]^{1 / 2}$

where $s$ is the sheltering coefficient. For the latter, Taitel and Dukler [50] proposed a value of 0.01 to match their experimental data. Andritsos [51], however, showed that this value is not accurate for gas flows with liquids of high viscosity and suggested a value of 0.06 based on their experiments. Xiao et al. [23] adopted the $s$ value of 0.06 for their model. This correlation (equation 1 ) served as the transition criteria from stratified-smooth to stratified-wavy flow regime. For the stratified to non-stratified transition, Xiao et al. [23] again adopted the theory proposed by Taitel and Dukler [50] model which assumes that a finite wave exists on the gas-liquid interface of an equilibrium stratified flow. The latter, extending the Kelvin-Helmholtz theory to analyse the stability of finite waves in pipes, claimed that when 
the pressure suction force is greater than the gravity force, waves tend to grow and thus stratified flow cannot be preserved. Their analysis led to the following criterion for this transition:

$$
v_{g}>\left(1-\frac{h_{L}}{D}\right)\left[\frac{\left(\rho_{L}-\rho_{g}\right) g \cos (\alpha) A_{g}}{\rho_{g}\left(\frac{d A_{L}}{d h_{L}}\right)}\right]^{1 / 2} v_{g}>\left(1-\frac{h_{L}}{D}\right)\left[\frac{\left(\rho_{L}-\rho_{g}\right) g \cos (\alpha) A_{g}}{\rho_{g}\left(\frac{d A_{L}}{d h_{L}}\right)}\right]^{1 / 2}
$$

It can be observed that the flow pattern transition equations, which are functions of fluid properties, capture the anticipation of wave development, during the flow. However, they seem not to account for liquid viscosity.

The TUFFP model [24] is capable of predicting bubble, stratified, slug and annular flows. Flow pattern equations for stratified flow are based on those which govern transition from slug flow. The main flow characteristic used for the transition is the behaviour of the liquid film of the slug, which the authors note, becomes infinitely long when the transition from slug flow to stratified (or annular) flow occurs. Given the superficial gas velocity, $v_{s g} v_{s g}$ and making a guess for the superficial liquid velocity, $v_{s l} v_{s l}$ the film liquid holdup is calculated, which value is used to calculate a new superficial liquid velocity which integrates liquid entrainment fraction.

$v_{s l}=\frac{v_{F} H_{L F}}{\left(1-F_{E}\right)} v_{s l}=\frac{v_{F} H_{L F}}{\left(1-F_{E}\right)}$

where $v_{F}, H_{L F} v_{F}, H_{L F}$ and $F_{E} F_{E}$ represent velocity of the liquid film, liquid film holdup and liquid entrainment droplet fraction respectively. The curve of $v_{s l} v_{s l}$ versus $v_{s g} v_{s g}$ in their established flow pattern map defines the boundary between slug flow and stratified (or annular flow). Further, due to lack of a definite boundary, the transition from stratified flow to annular flow was estimated using Grolman correlation [52] for wetted wall fraction, taking 0.9 as the transition criteria. The authors claimed that this ensured a continuous transition between stratified and annular flows for hydrodynamic calculations.

The Beggs and Brill [19] model broadly classifies the flow patterns into segregated (stratified-smooth, stratified-wavy and annular), intermittent (plug and slug) and distributed flows (bubble and mist). To predict the flow pattern, this model relies on the Froude number, no-slip holdup and empirically 
determined parameters, ${ }^{L_{1} L_{1}}$ to ${ }^{L_{4} L_{4}}$ which are functions of no-slip holdup. The representative mathematical expressions are presented in equations (4) to (6) as follows:

$$
N_{F r}=\frac{v_{m}^{2}}{g D} N_{F r}=\frac{v_{m}^{2}}{g D}
$$

$$
\lambda_{l}=\frac{v_{s l}}{v_{m}} \lambda_{l}=\frac{v_{s l}}{v_{m}}
$$

$$
\begin{aligned}
& L_{1}=316 \lambda_{l}^{0.302} L_{1}=316 \lambda_{l}^{0.302}, \quad L_{2}=0.0009252 \lambda_{l}^{-2.4684} L_{2}=0.0009252 \lambda_{l}^{-2.4684} ， \\
& L_{3}=0.10 \lambda_{l}^{-1.4516} L_{3}=0.10 \lambda_{l}^{-1.4516} L_{4}=0.5 \lambda_{l}^{-6.738} L_{4}=0.5 \lambda_{l}^{-6.738}
\end{aligned}
$$

In this model, the segregated flow regime is bounded by:

$$
\lambda_{l}<0.01 \text { and } N_{F r}<L_{1} \lambda_{l}<0.01 \text { and } N_{F r}<L_{1} \text { or } \quad \lambda_{l} \geq 0.01 \text { and } N_{F r}<L_{2}
$$

$\lambda_{l} \geq 0.01$ and $N_{F r}<L_{2}$

The Mukherjee and Brill [21] model predicts bubble, slug, stratified and annular-mist flow in horizontal and inclined pipes. The flow pattern map is based on empirically determined and dimensionless gas and liquid velocity numbers. The model proposed that horizontal stratified flow regime occurs when the liquid velocity number, ${ }^{N_{l v}} N_{l v}$ is greater than transitional liquid velocity number, $N_{l v S T} N_{l v S T}$, where:

$$
\begin{aligned}
& N_{l v S T}=10\left[0.321-0.017 N_{g v}-4.267 \sin \theta-2.972 N_{l}-0.033\left(\log _{10} N_{g v}\right)^{2}-3.925 \sin ^{2} \theta\right] \\
& N_{l v S T}=10\left[0.321-0.017 N_{g v}-4.267 \sin \theta-2.972 N_{l}-0.033\left(\log _{10} N_{g v}\right)^{2}-3.925 \sin ^{2} \theta\right]
\end{aligned}
$$

and the subscript ST refers the stratified transitions.

$$
N_{l v}=v_{s l} \sqrt[4]{\frac{\rho_{l}}{g \sigma}} N_{l v}=v_{s l} \sqrt[4]{\frac{\rho_{l}}{g \sigma}}, N_{g v}=v_{s g} \sqrt[4]{\frac{\rho_{l}}{g \sigma}} N_{g v}=v_{s g} \sqrt[4]{\frac{\rho_{l}}{g \sigma}} \quad N_{l}=\mu_{l} \sqrt[4]{\frac{g}{\rho_{l} \sigma^{8}}} N_{l}=\mu_{l} \sqrt[4]{\frac{g}{\rho_{l} \sigma^{8}}}
$$


The model proposed that the annular-mist flow regime occurs when the gas velocity number, ${ }_{g v} N_{g v}$ is greater than transitional gas velocity number, ${ }_{\text {gvS }} N_{\text {gvSM }}$, where:

$$
N_{g v S M}=10\left[1.401-2.694 N_{l}+0.521 N_{l v}^{0.329}\right] N_{g v S M}=10\left[1.401-2.694 N_{l}+0.521 N_{l v}^{0.329}\right]
$$

and the subscript SM refers the slug-annular transitions.

\subsubsection{Liquid Holdup Prediction}

To predict total liquid holdup, ${ }_{l} H_{l}$, in the stratified flow regime, using the Xiao et al. [23] model, the film thickness was determined and applied using the following equations:

$$
H_{l}=\frac{\beta-\sin \beta}{2 \pi} H_{l}=\frac{\beta-\sin \beta}{2 \pi} \text {, where }
$$

$$
\beta=2 \cos ^{-1}\left(1-2 \frac{h_{L}}{D}\right) \beta=2 \cos ^{-1}\left(1-2 \frac{h_{L}}{D}\right)
$$

For annular flow, total liquid holdup is calculated as:

$$
H_{l}=1-\left(1-2 \frac{h_{L}}{D}\right)^{2} \frac{v_{s g}}{v_{s g}+v_{s l} F E} H_{l}=1-\left(1-2 \frac{h_{L}}{D}\right)^{2} \frac{v_{s g}}{v_{s g}+v_{s l} F E}
$$

(2) The liquid phase in annular flow in horizontal pipes exists in two forms; liquid film flowing along the pipe wall and liquid droplets entrained in the gas core. Unlike the case of vertical flow, the liquid film is not circumferentially uniform but is thicker at the bottom than at the upper periphery of the pipe. This behaviour is captured by $\frac{h_{L}}{D} \frac{h_{L}}{D}$, representing the dimensionless liquid film thickness. In this model, it is solved from the combined momentum equation.

The TUFFP model [24] assumes a flowing film of liquid and predicts the liquid holdup as: 


$$
H_{L F}=\frac{\left(H_{L S}\left(v_{T}-v_{S}\right)+v_{S l}\right)\left(v_{S g}+v_{S l} F_{E}\right)-v_{T} v_{S l} F_{E}}{v_{T} v_{S g}} H_{L F}=\frac{\left(H_{L S}\left(v_{T}-v_{S}\right)+v_{S l}\right)\left(v_{s g}+v_{S I} F_{E}\right)-v_{T} v_{S l} F_{E}}{v_{T} v_{S g}}
$$

For the segregated flow pattern, the Beggs and Brill model [19] predicts liquid holdup as:

$$
H_{l(o)}=\frac{0.98 \lambda^{0.4846}}{N_{F R}^{0.0868}} H_{l(o)}=\frac{0.98 \lambda^{0.4846}}{N_{F R}^{0.0868}}
$$

The Mukherjee and Brill model [21] employs a general empirical model to predict total liquid holdup for uphill and horizontal flows for all flow patterns:

$$
\begin{aligned}
& H_{l}=\left(-0.380133+0.129875 \sin \theta-0.119788 \sin ^{2} \theta+2.343227 N_{L}^{2}\right) \frac{N_{g v}^{0.475686}}{N_{l v}^{0.288657}} \\
& H_{l}=\left(-0.380133+0.129875 \sin \theta-0.119788 \sin ^{2} \theta+2.343227 N_{L}^{2}\right) \frac{N_{g v}^{0.475686}}{N_{l v}^{0.288657}}
\end{aligned}
$$

The Lockhart and Martinelli model [20] is a flow pattern-independent separated model which assumes that the phases flow separately from each other with each phase flowing in a portion of the cross-sectional area of the pipe. It employs single-phase methods based on the hydraulic diameter concept. Matching conditions are required to couple the two phases to obtain a solution. For a given set of flow conditions, the solution is obtained by first calculating the Lockhart and Martinelli parameter, $\mathrm{X}$ (equation 17) culled from Shoham [20] as follows:

$$
X^{2}=\frac{\left(-\frac{d p}{d L}\right)_{S L}}{\left(-\frac{d p}{d L}\right)_{S G}}=\frac{\frac{2}{D} C_{L}\left[\frac{{ }_{s l} \rho_{l} D}{\mu_{l}}\right]^{-n} \rho_{l l} v_{s l}^{2}}{\frac{2}{D} c_{G}\left[\frac{v_{s g} \rho_{l} D}{\mu_{g}}\right]^{-m} \rho_{g} v_{S g}^{2}} X^{2}=\frac{\left(-\frac{d p}{d L}\right)_{S L}}{\left(-\frac{d p}{d L}\right)_{S G}}=\frac{\frac{2}{D} C_{L}\left[\frac{v_{s l} \rho_{l} D}{\mu_{l}}\right]^{-n} \rho_{l v_{s l}^{2}}}{\frac{2}{D} c_{G}\left[\frac{{ }_{s g} \rho_{l} D}{\mu_{g}}\right]^{-m} \rho_{g} v_{s g}^{2}}
$$

When calculating $X$, one should determine the liquid and gas flow regimes, namely laminar or turbulent. Values of the liquid holdup can then be determined from a graphical solution provided by the authors [20].

\subsubsection{Pressure Gradient Prediction}

The Beggs and Brill model determines the pressure drop (gradient) using equation (18) which represents the friction and gravitational pressure gradients respectively. Notably, the two-phase friction factor and 
the liquid holdup parameters play key roles. The two-phase friction factor, ${ }_{t p} f_{t p}$, is a function of normalized friction factor determined from the smooth pipe on the Moody diagram.

$$
\frac{d p}{d z}=\frac{\frac{f_{t p} \rho_{n} v \tilde{n}}{2 d}+\rho_{s g} \sin \theta}{1-E_{k}} \frac{d p}{d z}=\frac{\frac{f_{t p} \rho_{n} v \tilde{n}}{2 d}+\rho_{s} g \sin \theta}{1-E_{k}}
$$

$\rho_{n} \rho_{n}$ and $\quad \rho_{s} \rho_{s}$ represent no-slip and slip densities respectively.

Where $E_{k}=\frac{\rho_{s} \Delta\left(v_{m}^{2}\right)}{2 d p} E_{k}=\frac{\rho_{s} v_{s q} v_{m}}{p} \quad E_{k}=\frac{\rho_{s} v_{s q} v_{m}}{p} E_{k}=\frac{\rho_{s} v_{s q} v_{m}}{p}$

To calculate the pressure drop using the Lockhart and Martinelli model, as presented by Shoham [20], the Lockhart and Martinelli parameter, $X$, is determined from given input data. Calculation of the Lockhart and Martinelli parameter requires determination of the nature of the gas and liquid flow regimes, that is, whether they are turbulent or laminar. Corresponding values of either $\phi_{G} \phi_{G}$ or $\phi_{L}$ $\phi_{L}$

can be read from the graph. Depending on the choice of friction multiplier, friction pressure gradient (equation 20 and 21) can then be calculated as follows:

$$
\left(-\frac{d p}{d L}\right)_{L}=\phi_{l}^{2}\left(-\frac{d p}{d L}\right)_{S L}\left(-\frac{d p}{d L}\right)_{L}=\phi_{l}^{2}\left(-\frac{d p}{d L}\right)_{S L}
$$

$$
\left(-\frac{d p}{d L}\right)_{G}=\phi_{g}^{2}\left(-\frac{d p}{d L}\right)_{S G}\left(-\frac{d p}{d L}\right)_{G}=\phi_{g}^{2}\left(-\frac{d p}{d L}\right)_{S G}
$$

Results presented on the graph are based on empirical data sets obtained from small diameter pipes sizes (ranging between $1.5 \mathrm{~mm}$ and $25.4 \mathrm{~mm}$ ) and liquids of various viscosities. It is also important to note that though the model focuses on prediction of friction-related pressure drop, it does not account for shear-stresses. In addition, the model neglects the gravitational component of the pressure drop, which is significant. Finally, equations to capture liquid droplet entrainment effects are absent in the calculations.

The Mukherjee and Brill model [21] employs a two-fluid mechanistic model to predict pressure drop for stratified (Equations 22 - 25) and annular (Equation 26) flows respectively. 
For stratified flow

$$
-A_{g}\left(\frac{d p}{d L}\right)=-\left(\tau_{w g} P_{g}+\tau_{i} W_{i}\right)-A_{g} \rho_{g} \sin \theta-A_{g}\left(\frac{d p}{d L}\right)=-\left(\tau_{w g} P_{g}+\tau_{i} W_{i}\right)-A_{g} \rho_{g} \sin \theta
$$

$\left(A-A_{g}\right)\left(\frac{d p}{d L}\right)=-\left(\tau_{w l}\left(\pi d-P_{g}\right)-\tau_{i} W_{i}\right)-A_{l} \rho_{l} \sin \theta$

$\left(A-A_{g}\right)\left(\frac{d p}{d L}\right)=-\left(\tau_{w l}\left(\pi d-P_{g}\right)-\tau_{i} W_{i}\right)-A_{l} \rho_{l} \sin \theta$

$P_{g}=(1-\delta / 2 \pi) P P_{g}=(1-\delta / 2 \pi) P$

(9)

$P=P_{l}+P_{g} P=P_{l}+P_{g}$

where $P$ is the total perimeter of the pipe

For annular flow

$\left(\frac{d p}{d L}\right)=\frac{f_{c} \rho_{n s} v_{m}^{2}}{2 g d}+\rho_{m} \sin \theta\left(\frac{d p}{d L}\right)=\frac{f_{c} \rho_{n s} v_{m}^{2}}{2 g d}+\rho_{m} \sin \theta$

$f_{c}=f_{R} f_{n s} f_{c}=f_{R} f_{n s}$, where $f_{n s} f_{n s}$ is the no-slip friction factor, calculated using the Colebrook equation

The TUFFP model [24] employs equations 27 or 28 to calculate the pressure drop (gradient).

$\frac{p_{2}-p_{1}}{l_{F}}=\frac{\rho_{l}\left(v_{T}-v_{F}\right)\left(v_{S}-v_{F}\right)}{l_{F}}+\frac{\tau_{I} S_{I}-\tau_{F} S_{F}}{H_{L F} A}-\rho_{l} g \sin \theta \frac{p_{2}-p_{1}}{l_{F}}=\frac{\rho_{l}\left(v_{T}-v_{F}\right)\left(v_{S}-v_{F}\right)}{l_{F}}+\frac{\tau_{I} S_{I}-\tau_{F} S_{F}}{H_{L F} A}-\rho_{l} g \sin \theta$

$\frac{p_{2}-p_{1}}{l_{F}}=\frac{\rho_{c}\left(v_{T}-v_{c}\right)\left(v_{S}-v_{C}\right)}{l_{F}}+\frac{\tau_{I} S_{I}-\tau_{c} S_{C}}{\left(1-H_{L F}\right) A}-\rho_{c} g \sin \theta \frac{p_{2}-p_{1}}{l_{F}}=\frac{\rho_{C}\left(v_{T}-v_{c}\right)\left(v_{S}-v_{C}\right)}{l_{F}}+\frac{\tau_{I} S_{I}-\tau_{c} S_{C}}{\left(1-H_{L F}\right) A}-\rho_{c} g \sin \theta$ 
Published in Heat and Mass Transfer, DOI: https://doi.org/10.1007/s00231-019-02616-y

The relevant equations employed in the Xiao et al. [23] model for pressure gradient prediction is shown in equations 29 to 35 .

For stratified flow

$-\left(\frac{d p}{d L}\right)=\frac{\tau_{w l} S_{l}+\tau_{w g} S_{g}}{A}+\left(\frac{A_{l}}{A} \rho_{l}+\frac{A_{g}}{A} \rho_{g}\right) g \sin \theta-\left(\frac{d p}{d L}\right)=\frac{\tau_{w l} S_{l}+\tau_{W g} S_{g}}{A}+\left(\frac{A_{l}}{A} \rho_{l}+\frac{A_{g}}{A} \rho_{g}\right) g \sin \theta$

where $\tau_{w l}=f_{f} \frac{\rho_{l} v_{l}^{2}}{2} \tau_{w l}=f_{f} \frac{\rho_{l} v_{l}^{2}}{2}, \tau_{w g}=f_{w g} \frac{\rho_{g} v_{g}^{2}}{2}, \tau_{i}=f_{i} \frac{\rho_{g} v_{g}^{2}}{2} \tau_{w g}=f_{w g} \frac{\rho_{g} v_{g}^{2}}{2}, \tau_{i}=f_{i} \frac{\rho_{g} v_{g}^{2}}{2} \quad$ and

$f_{w l}, f_{w g} f_{w l}, f_{w g}$ is calculated from the following:

$f=\frac{16}{R_{e}}$, for $R_{e} \leq 2000 f=\frac{16}{R_{e}}$, for $R_{\theta} \leq 2000$

$\frac{1}{\sqrt{f}}=3.48-4 \log \left(\frac{2 \epsilon}{D}+\frac{9.35}{R e \sqrt{f}}\right)$, for $R_{e}>2000 \frac{1}{\sqrt{f}}=3.48-4 \log \left(\frac{2 \epsilon}{D}+\frac{9.35}{R e \sqrt{f}}\right)$, for $R_{e}>2000$

$\operatorname{Re} e_{l}=\frac{\rho_{l} v_{l} D_{l}}{\mu_{l}} R e_{l}=\frac{\rho_{l} v_{l} D_{l}}{\mu_{l}}, R e_{g}=\frac{\rho_{g} v_{g} D_{g}}{\mu_{g}}, R e_{g}=\frac{\rho_{g} v_{g} D_{g}}{\mu_{g}}, \quad D_{l}=\frac{4 A_{l}}{s_{l}} D_{l}=\frac{4 A_{l}}{s_{l}} \quad D_{g}=\frac{4 A_{g}}{s_{g}} D_{g}=\frac{4 A_{g}}{s_{g}}$
Using

$D_{l} D_{l}$ and $D_{g} D_{g}$ represent the hydraulic diameters

For annular flow

$-\left(\frac{d p}{d L}\right)=\frac{\tau_{W l} S_{l}+\tau_{W g} S_{g}}{A}+\left(\frac{A_{f}}{A} \rho_{l}+\frac{A_{C}}{A} \rho_{g}\right) g \sin \theta-\left(\frac{d p}{d L}\right)=\frac{\tau_{W l} S_{l}+\tau_{W g} S_{g}}{A}+\left(\frac{A_{f}}{A} \rho_{l}+\frac{A_{C}}{A} \rho_{g}\right) g \sin \theta$

where $\tau_{w l}=f_{f} \frac{\rho_{l} v_{l}^{2}}{2} \tau_{w l}=f_{f} \frac{\rho_{l} v_{l}^{2}}{2}, \tau_{i}=f_{i} \frac{\rho_{c}\left(v_{c}-v_{f}\right)^{2}}{2}, \tau_{i}=f_{i} \frac{\rho_{c}\left(v_{c}-v_{f}\right)^{2}}{2}$ and 
$f_{f} f_{f}$

is calculated from the following:

$f=\frac{16}{R_{e}}$, for $R_{e} \leq 2000 f=\frac{16}{R_{e}}$, for $R_{e} \leq 2000$

$\frac{1}{\sqrt{f}}=3.48-4 \log \left(\frac{2 \epsilon}{D}+\frac{9.35}{R e \sqrt{f}}\right)$, for $R_{e}>2000 \frac{1}{\sqrt{f}}=3.48-4 \log \left(\frac{2 \epsilon}{D}+\frac{9.35}{R e \sqrt{f}}\right)$, for $R_{e}>2000$

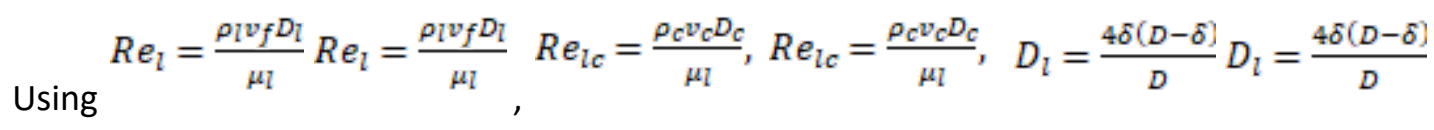

$$
\begin{aligned}
& v_{f}=\frac{v_{s l}(1-F E)}{4 \frac{\delta}{D}\left(1-\frac{\delta}{D}\right)} v_{f}=\frac{v_{s l}(1-F E)}{4 \frac{\delta}{D}\left(1-\frac{\delta}{D}\right)}, v_{c}=\frac{v_{s g}+v_{s l}(1-F E)}{\left(1-\frac{\delta}{2 D}\right)^{2}} v_{c}=\frac{v_{s g}+v_{s l}(1-F E)}{\left(1-\frac{\delta}{2 D}\right)^{2}} \quad f_{i}=f_{c}\left[1+2250 \frac{\left(\frac{\delta}{D}\right)}{\frac{\rho_{c}\left(v_{c}-v_{f}\right)^{2} \delta}{\sigma}}\right] \\
& f_{i}=f_{c}\left[1+2250 \frac{\left(\frac{\delta}{D}\right)}{\frac{\rho_{c}\left(v_{c}-v_{f}\right)^{2} \delta}{\sigma}}\right]
\end{aligned}
$$

The liquid entrainment fraction correlation presented by Oliemans et al [53] was utilized in this model.

\section{METHODOLOGY}

\subsection{Description of the Flow Facility}

The experiment was implemented on a test rig capable of inclinations from $0 \sim 90^{\circ}$ (Figure 1 ) at the Gas Lift Innovation Centre, Yangtze University, China. For two-phase flow, the desired volume of oil was pumped into a mixing tank, and pressurized. After pressure stabilization and measurement, the liquid is mixed with compressed gas and introduced into the test section. The liquid returns to the mixing tank while the air is released into the atmosphere after the gas-liquid mixture has passed through the separator. For three-phase flow, oil and water were pumped into the mixer, stirred continuously till a homogeneous mixture is achieved, mixed with gas and introduced int the test section.

(a)

(b) 

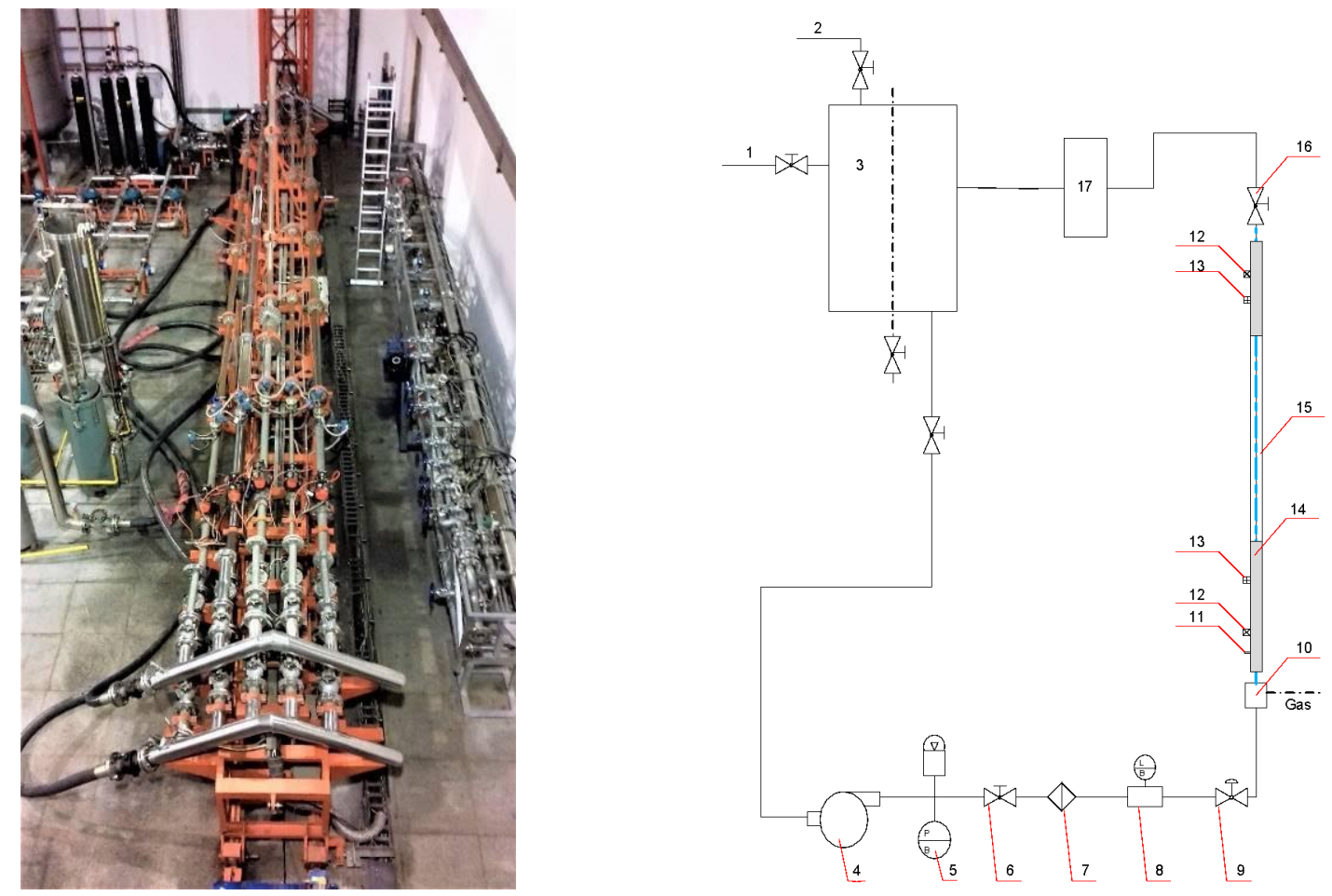

(c)

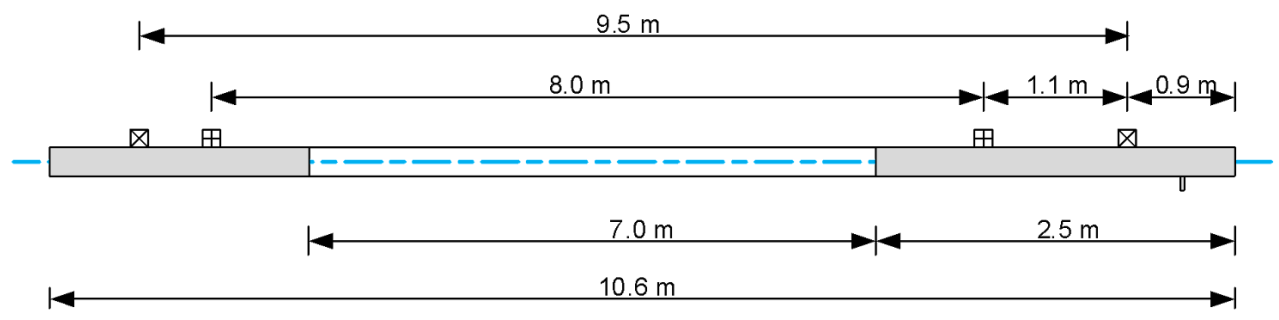

Figure 1. Experimental setup - (a) photo of the test rig, (b) schematic diagram with numbers denoting (1) Flow Entrance of Oil (2) Flow Entrance of Water (3) Oil-Water Mixer (4) Liquid Pump (5) Pressure Meter (6) Regulator (7) Moisture Content Tester (8) Flow Meter (9) Adjusting Pressure Valve (10) Gas-Liquid Mixer (11) Drain Pipe (12) Quick Closing Valve (QCV) (13) Differential Pressure Transducer (14) Stainless Steel Section (15) Viewing Section (16) Valve (17) Gas-Liquid Separator, (c) Test section positions of QCVs and Pressure transducers

The test section (Figure 1) is a pipe of length $10.6 \mathrm{~m}$ and an ID of $0.075 \mathrm{~m}$. The viewing section consists of an acrylic tube with a length of $7 \mathrm{~m}$. Stainless steel pipes of lengths $1.1 \mathrm{~m}$ and $2.5 \mathrm{~m}$ respectively are fixed at each end of the acrylic tube. Pressure, temperature and pressure differential sensors, as well as quick closing valves and other devices are installed on the stainless-steel sections of the pipe. The distance between the two quick closing valves is $9.5 \mathrm{~m}$. The distance between the differential pressure transducers is $8 \mathrm{~m}$. Control of the devices as well as extraction of data is done directly online at the control center. Details of the measuring equipment utilized for the experiment are presented in Table 1. Air constituted the gas phase while oil and an oil-water mixture respectively were used as the liquid phase. The fluid properties are presented in Table 2 . The variation of oil viscosity with temperature is also presented in Figure 2. 
Published in Heat and Mass Transfer, DOI: https://doi.org/10.1007/s00231-019-02616-y

Table 1: Details of the measuring equipment utilized for the experiment

\begin{tabular}{cccc}
\hline Equipment & Parameter measured & Measuring range & Measurement error \\
\hline Rosemount 305 1S & Pressure & $0 \sim 3.5 \mathrm{MPa}$ & $\pm 0.1 \%$ \\
Pressure transducers & & & \\
Endress+Hauser/80E50 & Liquid Flow Rate & $2 \sim 20 \mathrm{~m}^{3} / \mathrm{h}$ & $\pm 0.3 \%$ \\
Endress+Hauser/65F1H & Gas Flow Rate & $160 \sim 2000 \mathrm{~m}^{3} / \mathrm{h}$ & $\pm 1 \%$ \\
Rosemount 305 1S & Pressure Drop & $0-0.249 \mathrm{MPa}$ & $\pm 0.1 \%$ \\
Differential pressure & & & \\
\hline
\end{tabular}

Table 2: Fluid properties used in the experiment

\begin{tabular}{|c|c|c|c|}
\hline & Gas & & Liquid \\
\hline Fluid & Air & Oil & Water \\
\hline Density ( $\mathrm{kg} / \mathrm{m}^{3} \mathrm{~kg} / \mathrm{m}^{3}$ ) & 1.205 & 820 & 1000 \\
\hline Viscosity ( $\left.{ }^{m P a s m P a s}\right)$ & $0.0181\left(20^{\circ} \mathrm{C}\right)$ & $11.33\left(20^{\circ} \mathrm{C}\right)$ & 1 \\
\hline $\begin{array}{c}\text { Surface tension ( } \\
\qquad N / m \\
\text { ) }\end{array}$ & - & $0.0287\left(20^{\circ} \mathrm{C}\right)$ & $0.071\left(20^{\circ} \mathrm{C}\right)$ \\
\hline
\end{tabular}

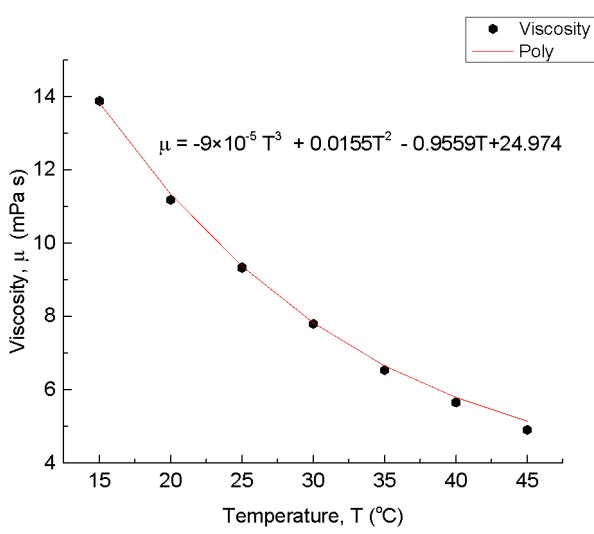

Figure 2: Variation of oil viscosity with temperature

\subsection{Experimental Procedure and Measurement}

For this study, a constant liquid flow rate was maintained, while the gas flow rate is adjusted. When the system was deemed steady (approximately 10 minutes from the start of the experiment), the experimental flow pattern was observed and recorded. Except for liquid holdup, all other experimental data were recorded every 5 seconds for 3 minutes, and finally the average value of each measurement parameter was obtained. Each complete test took approximately 20 minutes depending on the time required to reach steady-state. After the data recording is completed, the quick closing valve is closed trapping fluids flowing in the test section. The liquid holdups are measured by using a $9.5 \mathrm{~m}$ longitudinal pipe section. The quick closing valve has a response time is $0.3 \sim 0.5 \mathrm{~s}$. The trapped oil-water-air mixture is allowed to settle for 5 minutes and the pipe raised to facilitate draining of the liquid into a measuring 
cylinder. The liquid holdup is determined by calculating the volume of the liquid and dividing it by the volume of pipe-section. Flow patterns were visualized directly and also observed using a Canon Xtra NX4-S1 high-speed camera capable with a pixel resolution of resolution of 1024×1024 up to 3000 frames per second (fps). The maximum frame rate is $50,000 \mathrm{fps}$ with a reduced resolution. Videos and pictures of the flow pattern were obtained and used for analysis during the study. The range of measurements taken during the experiments is presented in Table 3.

Fully developed flow is a key requirement for studying the behaviour of multiphase flows. For this experiment, observations with the camera were made at $L / D=133$ and at this location it was assumed that the flow was fully developed. A survey of similar experiments indicates that fully developed flow patterns in horizontal pipes were reported at lower L/D values by a number of researchers including Oddie et al. [41] (L/D=73.3) and Ajay et al. [54] (L/D=98.4). We were therefore convinced that our L/D of 133 represents a more than sufficient flow development length.

Table 3: Range of experimental conditions

\begin{tabular}{cc}
\hline Superficial liquid velocity $(\mathrm{m} / \mathrm{s})$ & $0.03-0.13$ \\
Superficial gas velocity $(\mathrm{m} / \mathrm{s})$ & $1.27-40.37$ \\
Pressure $(\mathrm{MPa})$ & $0.01-0.07$ \\
Temperature $\left({ }^{\circ} \mathrm{C}\right)$ & $10.65-29.69$ \\
Pressure Drop $(\mathrm{kPa})$ & $0.03-5.70$ \\
Liquid Holdup $(-)$ & $0.039-0.532$ \\
Water-cut $(\%)$ & $0-90$ \\
\hline
\end{tabular}

\section{RESULTS AND DISCUSSIONS}

\subsection{Flow Pattern Description}

Two- and three-phase flow patterns have been studied and classified by several authors $[9,12,14,50$, 55-60]. In gas-oil-water flow, both gas-liquid and oil-water flow patterns are often observed at the same time. However, due to the homogeneous nature of the oil-water mixture in this experiment, three-phase flow patterns were not considered. Categorization of observed flow patterns were limited to gas-liquid classification. Similarities in observed flow patterns were found in reports by Spedding and Spencer [61], Hewitt [15] (when the oil-water is considered fully mixed) as well as Karami et al. [14]. Variations in temperature influenced the liquid viscosity for both two- and three-phase flows. Variations in liquid viscosity, in turn, affected the superficial liquid Reynolds numbers. It was found that liquid viscosity influenced the flow conditions at which two- and three-phase flows exhibited flow patterns observed during the study. ${ }^{R e_{l}}{ }^{R e_{l}}$ values are reported as a range to account for this phenomenon.

Flow patterns observed during the study include stratified smooth, stratified wavy (2-dimensional (2D)), 3-dimensional (3D), roll waves and stratified-annular [12] also described as atomization [14] or entrained droplet flow $[36,62]$. The appearance of waves at the gas-liquid interface can be considered transition 
from the stratified smooth to the stratified-wavy flow. This can be attributed to the Kelvin-Helmholtz instability theory $[51,63]$. The wave structures changed with varying flow conditions.

Generally, when the gas flow rate was increased, 2D waves appeared at the interface first and later gave way to 3-D waves which were replaced with more irregular roll waves and finally atomization of liquid droplets. At low superficial phase velocities (low superficial gas and liquid Reynolds numbers) stable stratified smooth flow was observed for all water-cuts (Figure 3, first row). The stratified smooth regime did not cover a wide range of gas flow rates. Transition to stratified-wavy (2D flow) was observed at $R e_{g}$ $R e_{g}$ of approximately 19392 and ${ }^{R e_{l}} R e_{l}$ values of 591 and 592 for water-cuts of $0 \%$ and 30\% respectively (Figure 3, second row). As can be observed, there are no ripples on the liquid surface at these conditions for water-cut of $60 \%$ and $90 \%$ respectively. For these water-cuts, transitions occurred at $R e_{g} R e_{g}$ of approximately 29685 and 26950 respectively and were marked with gentle ripples. The 2D waves extended across the entire pipe section and included interface movements and liquid level fluctuations only in the vertical direction.

\begin{tabular}{|c|c|c|c|c|}
\hline \multirow[b]{3}{*}{$v_{s g}(m / s)$} & Two-phase & \multicolumn{3}{|c|}{ Three-phase } \\
\hline & $0 \%$ & $30 \%$ & $60 \%$ & $90 \%$ \\
\hline & & & & \\
\hline \multicolumn{5}{|c|}{$v_{s g}(m / s)$} \\
\hline \multicolumn{5}{|c|}{$R e_{g}(-)$} \\
\hline \multirow{2}{*}{\multicolumn{5}{|c|}{$R e_{g}(-)$}} \\
\hline & & & & \\
\hline \multirow{3}{*}{$\begin{array}{c}1.99 \\
(9895)\end{array}$} & Pen & 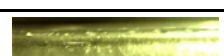 & Enere & ench \\
\hline & $R e_{l}=R e_{l}=$ & $R e_{l}=R e_{l}=$ & $R e_{l}=R e_{l}=$ & $R e_{l}=R e_{l}=$ \\
\hline & 296, SS & 261, SS & 469, SS & 1344, SS \\
\hline \multirow{4}{*}{$\begin{array}{c}3.9 \\
(19392)\end{array}$} & sens & 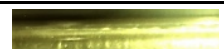 & honest & 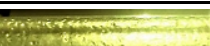 \\
\hline & & get? & & \\
\hline & $R e_{l}=R e_{l}=$ & $R e_{l}=R e_{l}=$ & $R e_{l}=R e_{l}=$ & $R e_{l}=R e_{l}=$ \\
\hline & $591, \mathrm{SW}(2 \mathrm{D})$ & 592, SW (2D) & $\begin{array}{l}939, \\
\text { SS }\end{array}$ & $\begin{array}{l}2687 \\
\text { SS }\end{array}$ \\
\hline 7.9 & 5 & 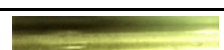 & & $\bar{E}$ \\
\hline (39282) & & & & \\
\hline
\end{tabular}




\begin{tabular}{|c|c|c|c|c|}
\hline & $\begin{array}{c}R e_{l}=R e_{l}= \\
591 \\
\text { SW (3D) }\end{array}$ & $\begin{array}{l}R e_{l}=R e_{l}= \\
592, \mathrm{SW}(3 \mathrm{D})\end{array}$ & $\begin{array}{l}R e_{l}=R e_{l}= \\
939, \mathrm{SW}(3 \mathrm{D})\end{array}$ & $\begin{array}{c}R e_{l}=R e_{l}= \\
2687, \mathrm{SW}(3 \mathrm{D})\end{array}$ \\
\hline $\begin{array}{c}19.6 \\
(97459)\end{array}$ & 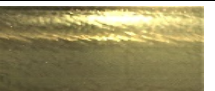 & 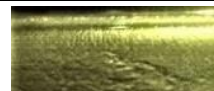 & $\sqrt{2+5 \sin }$ & 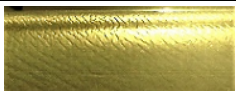 \\
\hline & $\begin{array}{c}R e_{l}=R e_{l}= \\
814 \\
\text { SW }(R W)\end{array}$ & $\begin{array}{c}R e_{l}=R e_{l}= \\
718 \\
\mathrm{SW}(\mathrm{RW})\end{array}$ & $\begin{array}{c}R e_{l}=R e_{l}= \\
1290 \\
\mathrm{~A}(\mathrm{~A})\end{array}$ & $\begin{array}{c}R e_{l}=R e_{l}= \\
3695 \\
\mathrm{~A}(\mathrm{~A})\end{array}$ \\
\hline $\begin{array}{c}39.2 \\
(194917)\end{array}$ & $=0$ & $x_{2}$ & 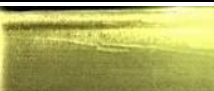 & - \\
\hline & $\begin{array}{c}R e_{l}=R e_{l}= \\
814 \\
\text { A (A) }\end{array}$ & $\begin{array}{c}R e_{l}=R e_{l}= \\
718 \\
\mathrm{~A}(\mathrm{~A})\end{array}$ & $\begin{array}{c}R e_{l}=R e_{l}= \\
1290 \\
\mathrm{~A}(\mathrm{~A})\end{array}$ & $\begin{array}{c}R e_{l}=R e_{l}= \\
3695 \\
\text { A (A) }\end{array}$ \\
\hline
\end{tabular}

Figure 3: Flow Pattern for (a) 0\% (b)30\% (c) $60 \%$ (d) $90 \%$ at various superficial phase velocities. SS (stratified smooth) flow, SW (2D) stratified wavy (2 Dimensional) flow, SW (3D) stratified wavy (3 Dimensional) flow, SW (RW) stratified wavy (roll waves) flow, SA (A) annular (atomization)

Transition to and onset of 3D flow also varied for different water-cuts in terms of superficial liquid Reynolds number. It was observed that at increasing water-cut in the three-phase flow higher superficial liquid Reynolds numbers are required for this flow regime. Stratified wavy (3D) flow pattern at $R e_{g} R e_{g}$ value of 39282 and ${ }^{R e_{l} R e_{l}}$ values of 591, 592, 939 and 2687 for water-cut of $0 \%, 30 \%, 60 \%$ and $90 \%$ respectively is shown in Figure 3 (third row). At these flow conditions, rivulets could be observed in the inner upper periphery and side walls of the test section, especially for water-cut of $60 \%$ and $90 \%$. These became more pronounced as fluctuations in the wetted wall fraction increased. This phenomenon can also be attributed to secondary flows in the gas phase. The exact mechanism for the appearance of rivulets continues to elude researchers. However, some explanations have been offered by a few who have also observed it. The observation reported by Spedding and Spence [61] occurred within what they classified as stratified with roll wave as well as film and droplet regimes. The authors attributed it to wave washing and droplet deposition. Shmueli et al. [12] made a similar observation at water-cuts of $50 \%$ and $75 \%$ respectively. They also attributed it to oil viscosity and surface tension. Mori et al. [64] did not observe such a phenomenon. However, contrary to the general assertion that roll waves are the sole propagators of droplets, they reported the inception of droplets before the inception of roll waves at all viscosities. They attributed this observation to the action of small waves. Considering the conditions at which rivulets were observed, in this experiment, droplets produced by the small waves, as suggested by 
Mori et al. [64], could be the plausible explanation at lower values of ${ }_{s g} v_{s g}$. On the other hand, the occurrence of droplets as a result of roll waves and wave washing could explain the phenomenon at higher $v_{s g} v_{s g}$ values as suggested by Spedding and Spence [61].

The onset of atomization usually occurs in the roll wave regime [14]. For this study, however, the phenomenon could not be accurately estimated. It could be observed at high gas and liquid superficial velocities. The roll waves at the various water-cuts and flow conditions are presented in Figure 3 (fourth row). At ${ }^{R e_{g} R e_{g}}$ value of 97459 , roll waves are observed at water-cut of $0 \%$ and $30 \%$. At water-cut of $60 \%$ and $90 \%$, however, the flow pattern seemed to be transitioning to stratified annular flow at water-cut of $60 \%$ and $90 \%$. Also, a mist could be seen flowing over the liquid film while the upper periphery of the pipe was covered with rivulets of liquid. The tangential waves at the side walls became more pronounced and the fluctuation in the wetted wall level increased with increase gas and liquid velocities especially for water-cuts at $60 \%$ and $90 \%$ (Figure 3, fourth row). Also, the amplitude of the waves reduced comparative to the 2 - and 3D waves. Similar observations of atomization were reported by Fan et al. [45], Dong et al. [47] and Shmueli et al. [12]. At high liquid and gas flow rates, the stratified-annular (atomization) flow regime was observed at all water-cuts. This phenomenon occurred at ${ }^{R e_{g} R e_{g}}$ values of 194917 and $R e_{l} R e_{l}$ values of 814, 718, 1290 and 3695 for water-cut of $0 \%, 30 \%$, $60 \%$ and $90 \%$ respectively (Figure 3, fifth row). The slope of the waves became comparatively gentle during atomization at higher water-cuts. Similar observations were made by Shmueli et al. [12] and Karami et al. [14].

\subsection{Comparison with flow pattern maps of Mandhane et al (1974) and Taitel and Dukler} (1976)

The Mandhane et al. [56] flow pattern map is the most widely accepted regime map [61] using the superficial phase velocities as mapping parameters. The experimental data for water-cut of $30 \%$ and $90 \%$ was superimposed on the map for comparison (Figure 4). It can be observed that the map agrees with stratified-smooth data for three-phase flows. Though the flow pattern map of Mandhane et al. [48] does not predict the stratified-annular flow regime, the map captures it as annular possibly because of the similar characteristics. It seems to have slight difficulties predicting the upper boundary of the air-oil data for the stratified-wavy flow regime. This limitation can perhaps be attributed to the fact that it was developed with air-water mixtures. Overall, it can be concluded that the flow pattern map agrees with 
the data with water-cut. Experimental data for $0 \%$ and $90 \%$ water-cut is presented on the Taitel and Dukler [50] flow map in Figure 5. The Taitel and Dukler flow pattern map does not predict a stratified annular flow regime. Data points in this regime are predicted by the Taitel and Dukler map as annular flow. In general, it is found that the map also agrees with the experimental data.

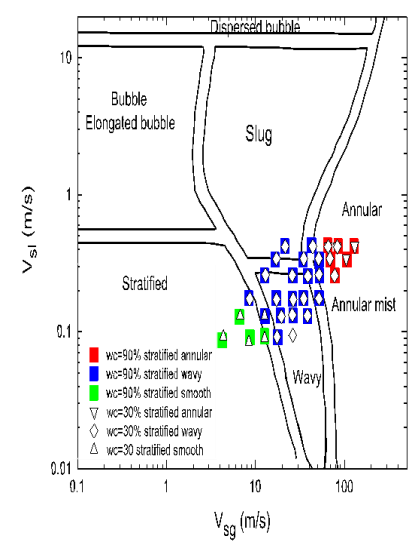

Figure 4: Comparison of experimental data with Mandhane et al. (1974) flow pattern map

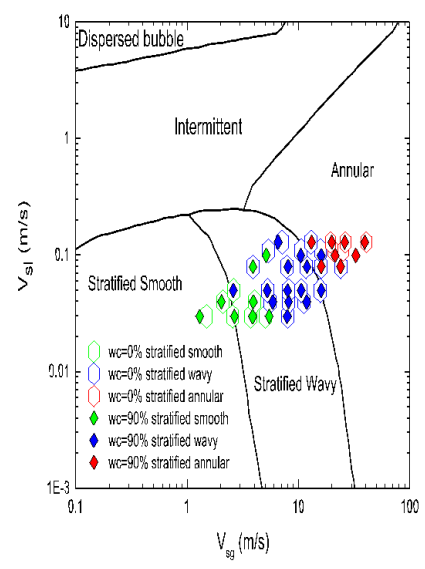

Figure 5: Comparison of experimental data with the Taitel and Dukler (1976) flow pattern map

\subsection{Liquid holdup}

Two- and three-phase characteristics of total liquid holdup were investigated using the experimental data collected. Liquid viscosity for both two- and three-phase flows were influenced by variations in temperature during the experiments. This, in turn, affected the superficial liquid Reynolds numbers. As a result, a range of ${ }^{R e_{l} R e_{l}}$ values were obtained for each superficial liquid velocity at each water-cut. 
Published in Heat and Mass Transfer, DOI: https://doi.org/10.1007/s00231-019-02616-y

For this study, ${ }^{R e_{l} R e_{l}}$ values varied from 160 to 4391 while ${ }^{R e_{g} R e_{g}}$ values varied from 6355 to 200757. It is shown that total liquid holdup decreases asymptotically when the superficial gas Reynolds number increases for all cases of water cut (Figure 6). Total liquid holdup is found to decrease more rapidly when superficial gas Reynolds number increases from 6315 to approximately 49724 for both twoand three-phase flows beyond which the decrease becomes gradual. An increase in gas velocity results in a rapid increase in liquid film velocity especially near the interface. Entrainment can occur, and hence a rapid decrease in liquid holdup. Further increases in the superficial gas velocity cannot increase the liquid film velocity significantly as a result of friction between the thin liquid film and the pipe wall, hence, a reduced rate of decrease of liquid holdup is observed. This result agrees with the findings of Dong et al. [47]. However, in the experimental study reported by Dong et al. [47], they observed that when the superficial gas velocity increases from 15 to $17.5 \mathrm{~m} / \mathrm{s}$, the liquid holdup even increases, explaining that within this velocity range, the wetted wall fraction continues to increase and a thin liquid film begins to form around the pipe due to deposition of the liquid droplet entrainment by the high-speed gas flow. As a result, the overall liquid velocity decreases because of the drag on the pipe wall, and the liquid holdup increases. As can be observed from Figure 6(a-d), such an observation was not made. Total liquid holdup loss can also be attributed to stronger wave structure and interfacial shear stresses as well as liquid entrainment (as a result of high superficial liquid velocity). High superficial gas velocities increase entrainment and hence reduced liquid holdup values.

(a)

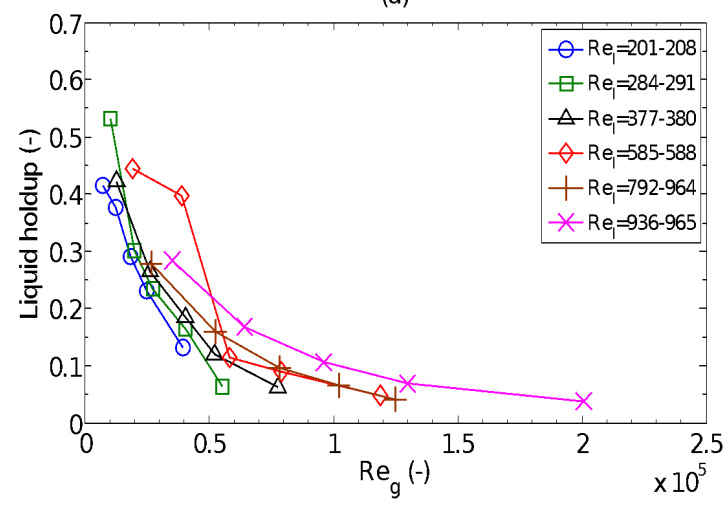

(b)

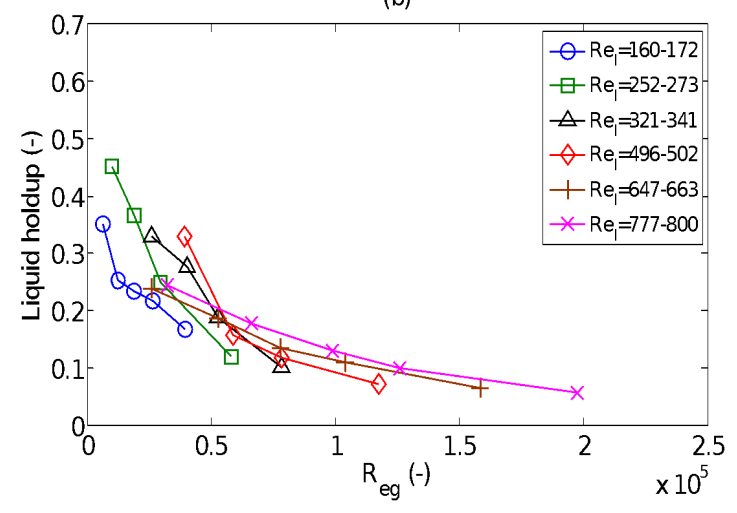


(c)

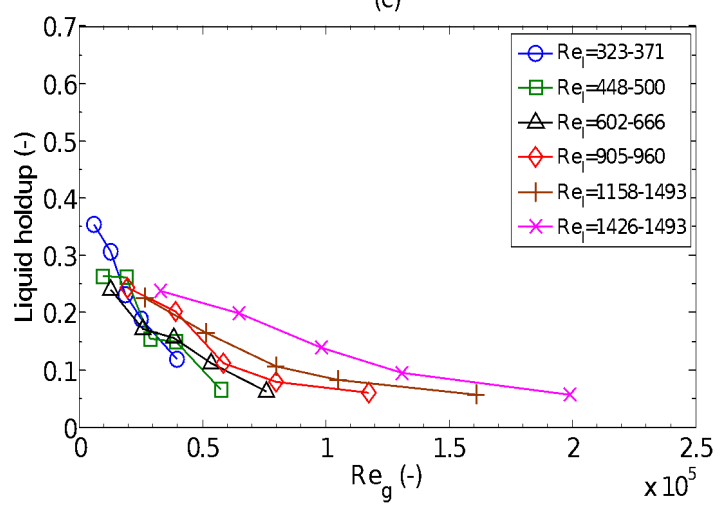

(d)

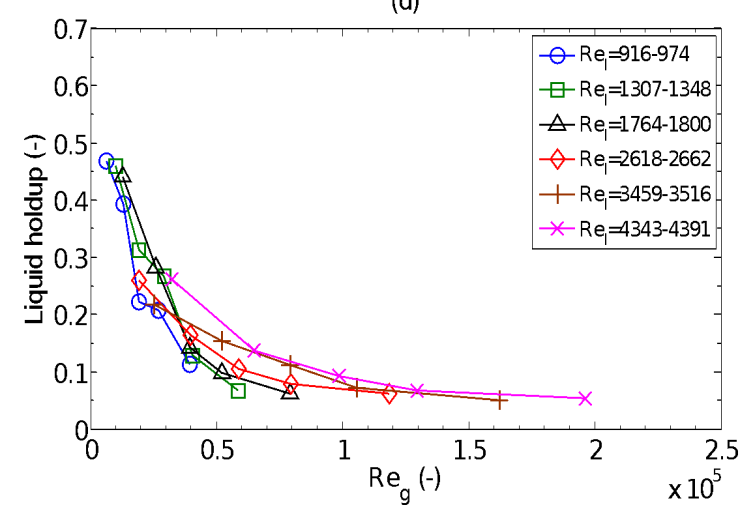

Figure 6: Variation of Liquid holdup with gas Reynolds number at (a) $0 \%$ (b) $30 \%$ (c) $60 \%$ (d) $90 \%$ water-cuts

At a fixed water-cut, it could be observed that total liquid holdup increases as superficial liquid velocity increases. The introduction of an additional volume of water is responsible for this phenomenon. However, some discrepancies are noteworthy. The effect of superficial liquid velocity is observed only beyond $R e_{\mathrm{g}} R e_{\mathrm{g}}$ values greater than 49723. Below this value, the effect of superficial liquid velocity is not obvious. It can also be noticed that at water-cut of $90 \%$, and at ${ }^{R e_{\mathrm{g}}} R e_{\mathrm{g}}$ values greater than 99448, the effect of liquid superficial velocity become negligible (Figure 6). No remarkable differences in twoand three-phase liquid holdup characteristics were observed.

Figures $7 \mathrm{a}$ and $7 \mathrm{~b}$ present the variation of total liquid holdup with superficial gas Reynolds number at different superficial liquid velocities and water-cut. Akin to the observations for pressure drop (Figure 8), the effect of water-cut on liquid holdup is not obvious. Though water-cut appears to exert some influence at lower superficial gas velocities, the effect is insignificant. Similar trends are observed at different superficial liquid velocities. The similarity in liquid mixture properties (density and viscosity) of the liquid properties to that of water as water-cut increases could be the reason for this observation. 
Despite the diameter differences, it is found that the observations agree with those of Karami et al. [14] and oppose that of Dong et al. [47] who observed that the liquid holdup decreases as water-cut increases for flows with oil-water mixtures.

(a)

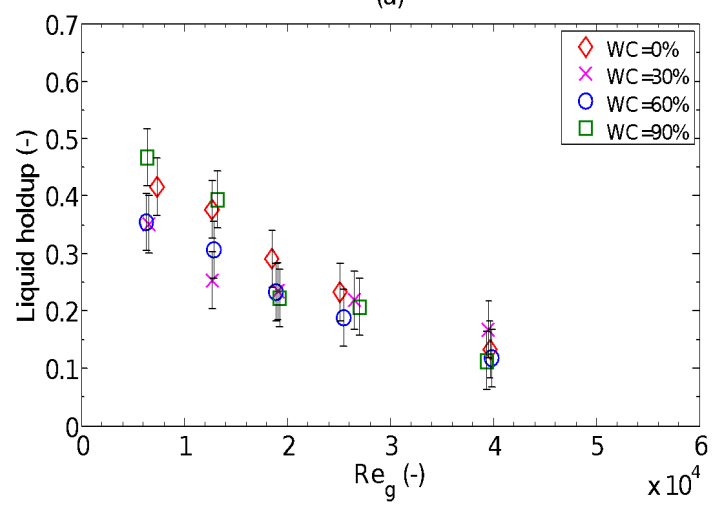

(b)

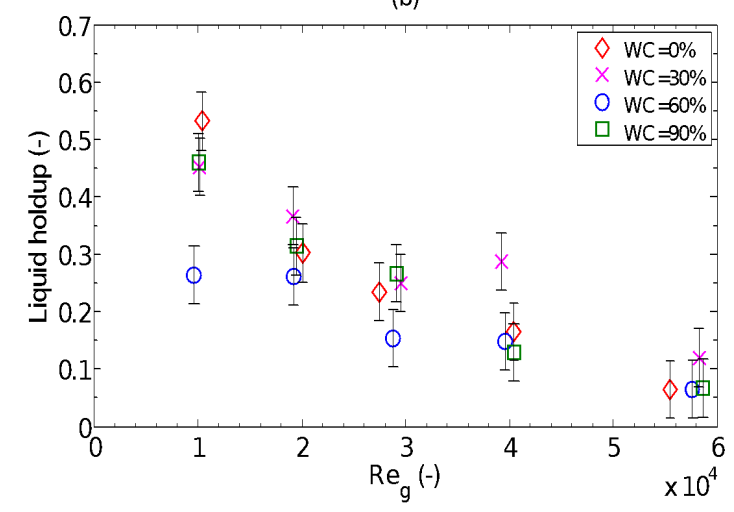

Figure 7: Variation of liquid holdup with superficial gas Reynolds number for different water-cuts at $v_{s l} v_{s l}$ values of (a) $0.03 \mathrm{~m} / \mathrm{s}$ and (b) $0.04 \mathrm{~m} / \mathrm{s}$

\subsection{Pressure Drop}

A plot of pressure drop against superficial gas Reynolds number is presented in Figure 8 for two- and three-phase flows at varied superficial liquid Reynolds numbers. Pressure drop increased as values of $R e_{g} R e_{g}$

increased for all cases of water-cut. This can be attributed to friction increase between the gas and the pipe wall and also at the gas-liquid interface. As suggested by Dong et al. [47], the presence of liquid reduces the flow area of gas, which increases the actual gas velocity and hence the pressure drop. The liquid forms a gas-liquid interface generating an interfacial friction which is normally higher than the gas-wall friction, especially when the gas-liquid interface becomes wavy. Further, the observation could be influenced by increments in the density of the gas phase as a result of entrained liquid. 
(a)

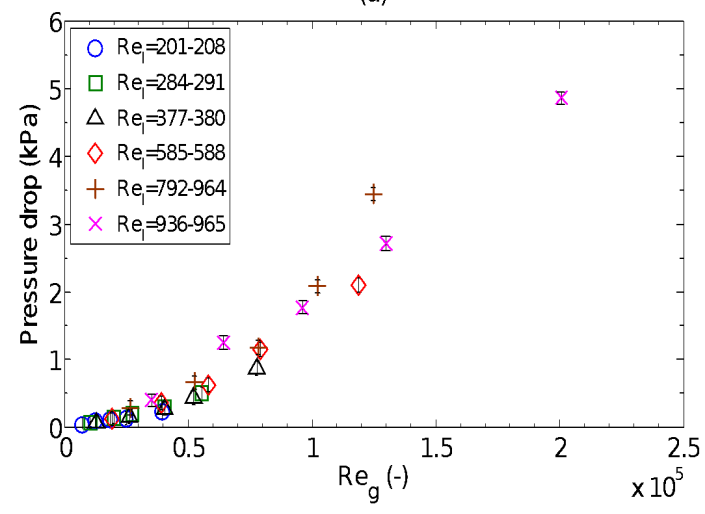

(b)

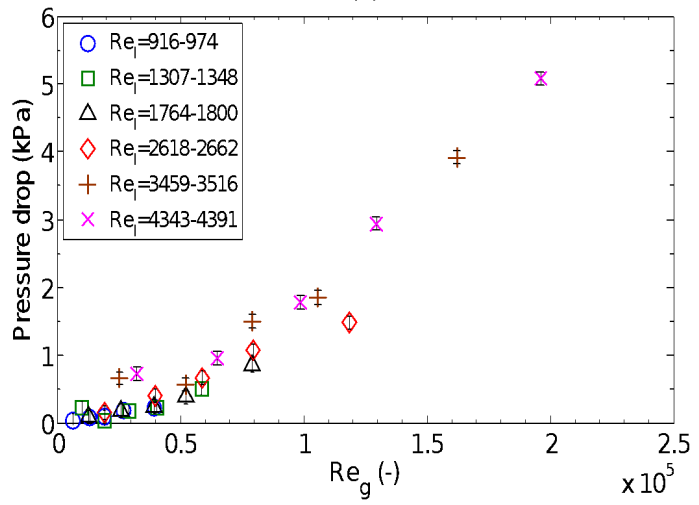

Figure 8: Variation of pressure drop with gas Reynolds number and liquid velocity at: (a) $0 \%$ and (b) $90 \%$ water-cut respectively

The results also revealed that water-cut and superficial liquid velocity do not have a significant effect on pressure drop (Figures 8). This could be attributed to the homogeneous nature of the oil-water mixture and negligible slip between the oil and water phases such that at each water-cut the three-phase mixture exhibits characteristics of two-phase flows. The trend can be related to the observed flow patterns. Increases in superficial gas velocity leads to flow pattern transitions from stratified smooth to stratified annular. As such, it was found that low pressure drops can be observed during stratified-smooth flows while high pressures drop could be associated with stratified-annular (entrainment-laden) flows. Further, decreasing liquid holdup corresponded to increases in pressure gradient for reasons discussed earlier (Figure 9). At relatively high liquid holdup values, corresponding to stratified-smooth flow pattern, the pressure drops are low. Pressure drop rapidly increases at transition to stratified-wavy and stratified annular flows even with gradual reduction in liquid holdup values. This trend was present for all values of water-cut.

In general, there is very little distinction between the two- and three-phase flow with respect to trends related to pressure drop. Comparison of findings on the relationships between pressure gradient and superficial phase velocities as well as water-cut indicate some agreement and differences with report in 
Published in Heat and Mass Transfer, DOI: https://doi.org/10.1007/s00231-019-02616-y

literature. For instance, the observations of Karami et al. [14], Dong et al. [47] and Al-Hadhrami et al. [10] agree with those of the study which finds that as superficial gas velocity increases, pressure gradient increases. On the other hand, the negligible effect of superficial liquid velocity is only endorsed by Karami et al. [14] who reported slight changes in pressure drop for two different values of superficial liquid velocity. Both Dong et al. [47] and Al-Hadhrami et al. [10] reported that superficial liquid velocity exerts significant influence on pressure gradient. Again, the weak influence of water-cut on pressure drop agrees with those of Karami et al. [14] and differ from the conclusions of Dong et al. [47] and Al-Hadhrami et al [10]. Dong et al. [47] observed that water-cut exerted some influence at higher superficial gas velocities $(17.5 \mathrm{~m} / \mathrm{s})$. They noted that pressure gradient increased with increasing water-cut from 0 to $50 \%$ and attributed it to increase in the effective liquid viscosity due water dispersion into the oil phase. On the other hand, pressure gradient was found to decrease with increasing water-cut from $50 \%$ to $100 \%$. They attributed this finding to inversion of dispersion to water continuous. The report from Al-Hadhrami et al. [10] indicated an initial increase and then decrease with increasing water-cut.

\subsection{MODEL EVALUATION}

\subsubsection{Flow Pattern Prediction}

For this study, the observed flow patterns were compared with the predictions of selected models integrated in the PIPESIM software [65]. Model predictions are assessed with respect to water-cut as well as the entire experimental data. The performance of the models for flow pattern prediction is displayed in Figure 9. The Lockhart and Martinelli [20] model presents no flow pattern. Therefore, no predictions are included in this assessment. From the results, it is found that at $0 \%$ water-cut (air-oil mixture), the Xiao et al [23] model exhibits the highest performance (66.7\%), followed by the Beggs and Brill (BB) [19] (43\%) and the TUFFP [24] (33\%) models respectively. The Mukherjee and Brill [21] model could only predict $20 \%$ of the experimental data. Compared to the Beggs and Brill model [19], the performance of the latter is surprising considering that the correlations were developed based on liquids of higher viscosities. 


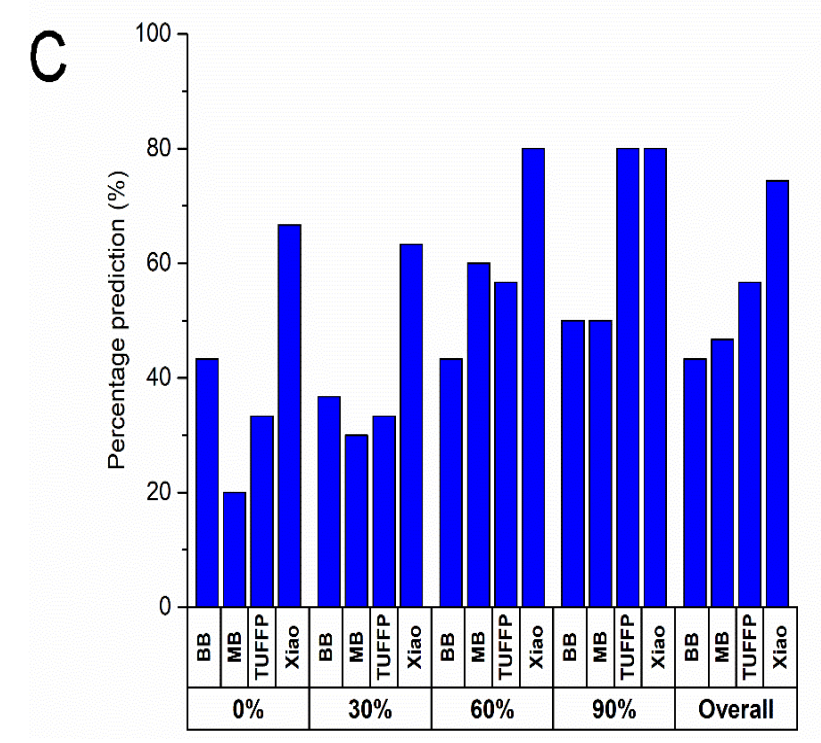

Figure 9: Percentage of the experimental Flow Pattern predicted by Beggs and Brill, Mukherjee and Brill, Lockhart and Martinelli, Xiao et al and TUFFP models at different water-cuts and the entire dataset

When the models are assessed with the three-phase flow data, it is found that at $30 \%$ water-cut, only the Xiao et al. [23] model presents a good performance. The Mukherjee and Brill (MB) [21] model showed an improved performance, at 30\% water-cut. When the water-cut is increased to $60 \%$, the Mukherjee and Brill model [21] exhibits a better performance over the Beggs and Brill and TUFFP models, only second to the Xiao et al. model. The Xiao et al. model exhibits the best performance at this water-cut. At $90 \%$ water-cut, the Xiao et al. as well as TUFFP models show the best performances. It is worth noting that the predictions of the Mukherjee and Brill model improves as water-cut increases, exhibiting the best performance when the water-cut is $60 \%$ but shows a reduced performance at $90 \%$ water-cut. Overall, the Xiao et al. model presents an outstanding performance (74\%) and consistency at predicting the flow pattern for all water-cuts. This is followed by the TUFFP model which predicts $57 \%$ of the flow pattern accurately. The Beggs and Brill as well as Mukherjee and Brill models accurately predict less than $50 \%$ of the observed flow patterns.

The Xiao et al. [23] model consistently performed well at all cases of water-cut considered. This can be attributed to the theory adopted from Taitel and Dukler [50] which captures the dynamics of possible occurrence of waves at the gas-liquid interface as well as suitable equations to describe the transitions from stratified-smooth to stratified wavy and from stratified-wavy to annular flow regimes. On the other hand, the approach adopted by the TUFFP model [24] could explain its low performance. The flow pattern prediction theory and correlation place emphasis on determination of characteristic liquid film as 
Published in Heat and Mass Transfer, DOI: https://doi.org/10.1007/s00231-019-02616-y

a transition criterion but fail to integrate the behaviour of the gas-liquid interface during stratified wavy flow regime. Furthermore, there are no delineating transition equations for stratified-smooth and stratified-wavy flow regimes.

The performance of the Beggs and Brill model [19] is found to be lower than expected, even at $90 \%$ water-cut when the properties of the mixture are close to that of water. This result can be attributed to a number of reasons. First, the correlations were developed based on air-water mixtures and smaller pipe diameters. The viscosity of liquids and pipe size employed in the experiment are higher than those employed in the development of the correlation. Also, it can be noticed that the authors lump stratified smooth, stratified wavy and annular flow into a single flow regime; segregated flow regime. Identification of the exact flow regime poses challenges. Further, the transition correlations are, basically, functions of phase velocities and do not account for the physical phenomena of wave growth and interfacial disturbances which occur during the stratified wavy flows. These seem to limit the correlation accuracy at predicting the experimental flow pattern.

Similarly, though the Mukherjee and Brill model [21] accounts for variations in viscosity, it is possible its overall low performance can be attributed to its inability to differentiate between stratified-smooth and stratified-wavy flow regimes as well as predict well the dynamics encountered in the stratified-wavy, 3D and roll wave regimes. The correlation was also developed with a smaller pipe diameter than was used for this study. This could be another limitation to accurate predictions.

\subsubsection{Consideration for liquid-liquid mixture viscosities}

As water-cut increases in liquid-liquid mixtures, a phenomenon is observed where there is a phase change. For accurate evaluation of the pseudo two-phase flow used in this study, therefore, the effective viscosity of the oil-water mixture had to be estimated. Several authors, including Brinkman [66], Einstein [67], Brauner [68], Becher [69] and Guet et al. [70] have proposed correlations for this estimation. The correlation proposed by Guet et al. [70] is a hybrid correlation which utilises the Becher [69] correlation (for dispersed water in oil conditions), a modified Becher [69] correlation (for cases where coalescence is playing an important role and the maximum drop size is significantly increased) and the continuous phase viscosity assumption ( for dispersion of oil in water conditions). Their results indicated that the proposed correlation was better results compared to predictions of the existing correlations. This correlation, however, is yet to be integrated into the PIPESIM software. The Brinkman [66] correlation has been utilized by some authors who have analyzed three-phase flows as a pseudo two-phase gas-liquid flow system with an effective viscosity and average properties determined for the 
Published in Heat and Mass Transfer, DOI: https://doi.org/10.1007/s00231-019-02616-y

liquid phase [15-17]. For this study, therefore, the Brinkman [66] correlation and the Brauner and Ullmann [71] correlations were activated in the simulator. The Brauner and Ullmann [71] correlation determined the point of phase inversion while the Brinkman [66] correlation determined the effective liquid mixture viscosity for each flow condition. The Brauner and Ullmann $[17,71]$ correlation is expressed as:

$c=1-\left[\frac{\rho_{t}^{0.6} \mu_{t}^{0.4}}{1+\rho_{t}^{0.6} \mu_{t}^{0.4}}\right] c=1-\left[\frac{\rho_{t}^{0.6} \mu_{t}^{0.4}}{1+\rho_{t}^{0.6} \mu_{t}^{0.4}}\right]$

where $\mathrm{c}$ is the cut-off/100, $\mu_{o} \mu_{o}, \mu_{w} \mu_{w}$ are the oil and water viscosities (cP)

$\rho_{t}=\frac{\rho_{0}}{\rho_{w}} \rho_{t}=\frac{\rho_{o}}{\rho_{w}}, \mu_{t}=\frac{\mu_{o}}{\mu_{w}} \mu_{t}=\frac{\mu_{0}}{\mu_{w}}$

The Brinkman [66] correlation calculates elevated emulsion viscosities on either side of the cut-off, using the formula:

$\mu_{m}=\mu_{c}\left(1-\phi_{d}\right)^{-2.5} \mu_{m}=\mu_{c}\left(1-\phi_{d}\right)^{-2.5}$

where $\mu_{c} \mu_{c}$ and $\phi_{d} \phi_{d}$ represent the viscosity of the continuous phase and the volume fraction of the discontinuous phase.

\subsubsection{Liquid Holdup and Gas Void Fraction}

Model predictions for liquid holdup, obtained using the PIPESIM software, are presented in two parts: as performance at (1) different water-cuts and (2) different ranges of liquid holdup. Liquid holdup values obtained from this experiment ranged from 0.039 to 0.532 . For the different ranges of liquid holdup values, predictions were assessed in three liquid holdup categories: $H_{l}<0.1 H_{l}<0.1,0.1 \leq H_{l} \leq 0.2$ $0.1 \leq H_{l} \leq 0.2$ and $H_{l}>0.2 H_{l}>0.2$. Statistical parameters used for the assessment are the average absolute percent error (AAPE) (Eq. 42) and average percent error (APE) (Eq. 43). A pictorial assessment of their performance compared to experimental data is presented in Figure 10 and 11 respectively. 
$A A P E=\left[\frac{1}{n} \sum_{m=1}^{n}\left|\frac{Y_{E x p, m}-Y_{\text {Pred,m }}}{Y_{\text {Exp }, m}}\right|\right] \times 100$ AAPE $=\left[\frac{1}{n} \sum_{m=1}^{n}\left|\frac{Y_{E x p, m}-Y_{P r e d, m}}{Y_{E x p, m}}\right|\right] \times 100$

$A P E=\left[\frac{1}{n} \sum_{m=1}^{n} \frac{Y_{E x p, m}-Y_{\text {Pred }, m}}{Y_{\text {Exp,m }}}\right] \times 100 A P E=\left[\frac{1}{n} \sum_{m=1}^{n} \frac{Y_{E x p, m}-Y_{\text {Pred, }}}{Y_{\text {Exp }, m}}\right] \times 100$

Where $Y_{\text {Exp,m }} Y_{\text {Exp,m }}$ and $Y_{\text {Pred,m }} Y_{\text {Pred,m }}$ represent experimental and predicted values respectively.

For two-phase flows (air-oil mixture) with the exception of the Lockhart and Martinelli correlation all the models exhibit satisfactory performances. The Xiao et al. model [23] presents an excellent performance with the least prediction errors (AAPE=25.67) and underprediction (APE=12.79) (Figure 10a). The behaviour of the liquid film appears central to prediction of liquid holdup in this model therefore it employs two different correlations for both the stratified and stratified-annular flow regimes. This approach seems to adequately capture the behaviour of the liquid film. Additionally, the correlation accounts for the effect droplet entrainment. It appears this approach yields more accurate results. The TUFFP model [24] comes second to the Xiao et al model and performs better than the empirical models. Unlike the Xiao et al. model, the TUFFP model utilizes a single correlation to predict liquid holdup for both the stratified and annular flow regimes. For the stratified and annular flow patterns, different interfacial friction factors are utilized to ensure the behaviour of the liquid film is captured. However, improved accuracy in flow pattern prediction could improve its performance. Again, the model underpredicts the experimental data with relatively modest prediction errors (AAPE=48.83). Similar findings of underprediction were reported by Karami et al. [14] from their study. The Beggs and Brill [19] as well as the Mukherjee and Brill [21] models exhibit relatively high errors and underprediction of the experimental data (Figure 10a). The relatively low performance of the models can be attributed to oversimplification in the methods employed to predict flow pattern. Both correlations lump the characteristics of three unique flow regimes. Lack of clear delineation of the flow regimes could be hindering accurate flow pattern prediction which influences correlations for liquid holdup prediction. The Beggs and Brill model is empirical in nature and difficulties to predict liquid holdup for at different flow and fluid conditions is to expected. In addition, liquid entrainment and the behaviour of the liquid film are not accounted for. The Mukherjee and Brill [21] model, however, exhibits a better performance (AAPE $=52.57$ ) possibly because the liquid properties are similar to those used for used for its development. With respect to the current experimental data, the performance of the Lockhart and 
Published in Heat and Mass Transfer, DOI: https://doi.org/10.1007/s00231-019-02616-y

Martinelli model [20] is found to be unsatisfactory because it exhibits the highest prediction errors and underprediction ( $A A P E=94.42, A P E=94.42$ ). For the development of the model, liquid hold data was obtained using pipe diameters smaller than what was used for this study. This was correlated with the Martinelli parameter to obtain a graphical solution. The relatively high underprediction is attributable to the empirical nature of the fitted curve between the two parameters.

For three-phase flow conditions, though all models underpredict the experimental data, they are found to exhibit a large degree of consistency across the water-cuts of $30 \%, 60 \%$ and $90 \%$ respectively (Figure 10b-d). This could be an indication that the approaches adopted can handle variations in fluid properties, especially properties of the composite liquid which characterise the three-phase (pseudo two-phase flows). The assumption of no-slip between the liquid-liquid interface appears to be valid which allows the models to make observed satisfactory predictions. It is also possible that the observed performances are as a result of the fact that estimated effective liquid viscosities are within ranges for which the correlations were developed. The consistent excellent prediction performance of the Xiao et al. [23] model is well noted (AAPE=45.09,33.61 and 35.91 for $30 \%, 60 \%$ and $90 \%$ water-cut respectively). In all cases, the latter exhibited the lowest prediction errors and underprediction. The overall performances of the models are satisfactory for the reasons discussed. The Xiao et al. [23] model exhibits the best performance, followed by TUFFP [24] and the Beggs and Brill [19] models respectively. The overall performance of the Xiao et al. [23] model is not surprising because it reflects the observations at all water-cuts. Considering that the same character of the flowing media is using to evaluate all models considered, the results indicate that the approach adopted by the models considered model for liquid holdup prediction can be considered applicable for pseudo two-phase flows, even with high water-cut. However, the methods adopted by Xiao et al. yield better results.

The number of combined two- and three-phase data points used for evaluation at the various holdup ranges,

$$
H_{l}<0.1 H_{l}<0.1,0.1 \leq H_{l} \leq 0.20 .1 \leq H_{l} \leq 0.2 \text { and } H_{l}>0.2 H_{l}>0.2 \text { are } 30,39 \text { and } 50
$$

respectively. Results of assessment of model predictions at various categories is presented in Figure 11.

The Beggs and Brill [19] model exhibits its best performance at $H_{l}<0.1 H_{l}<0.1$ (AAPE=52.94). While its prediction errors increase slightly at higher values of liquid holdup, they are satisfactory. Minami and Brill reported a similar observation while investigating liquid holdup in wet gas pipelines. They found that the Beggs and Brill correlation performed best at the $H_{l}<0.05 H_{l}<0.05$, which is even less than what was obtained in this study, while its efficiency reduced at higher holdup ranges. Further, at this range, 
the performance of the Mukherjee and Brill [21] model is also found to satisfactory, though its prediction errors seem to increase slightly with increasing liquid holdup ranges The TUFFP model [24] exhibits a satisfactory performance at $H_{l}<0.1 H_{l}<0.1 \quad$ (AAPE=56.85) as well as , $0.1 \leq H_{l} \leq 0.2$ $0.1 \leq H_{l} \leq 0.2$ (AAPE=56.19) categories. At $H_{l}>0.2 H_{l}>0.2$, however, its performance improves significantly (AAPE=42.86). The Xiao et al model [23] exhibits superior performance in all the classifications with relatively low prediction errors and underprediction. It is important to note that the predictions of the correlations improve as liquid holdup values increase. The model slightly overpredicts the experimental data at $H_{l}>0.2 H_{l}>0.2$, however, this occurs within acceptable limits. At $H_{l}<0.1$ $H_{l}<0.1$, the Xiao et al. [23] model exhibits the best performance. With the exception of the Lockhart and Martinelli [20] model, the rest exhibit similar satisfactory performances. At $0.1<H_{l}<0.2$ $0.1<H_{l}<0.2$, $H_{l}>0.2 H_{l}>0.2$ and $H_{l}>0.2 H_{l}>0.2$, the Xiao et al. [23] model presents the best performance followed by the TUFFP [24] model. 


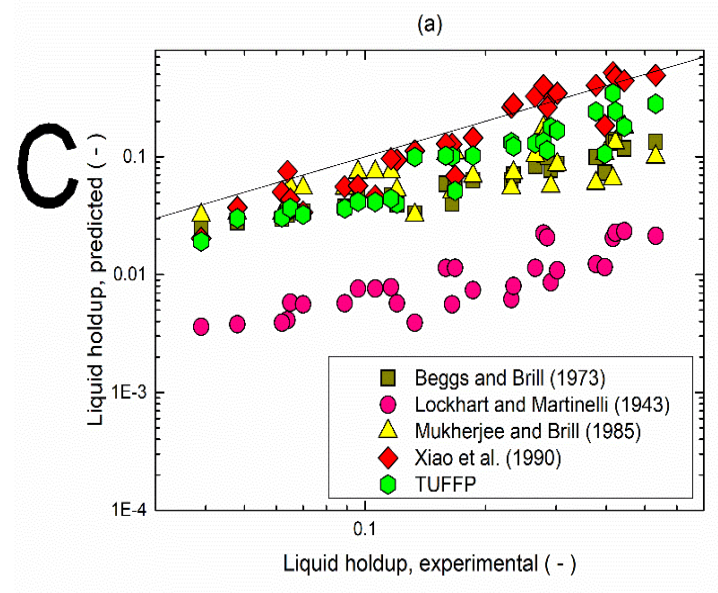

(b)

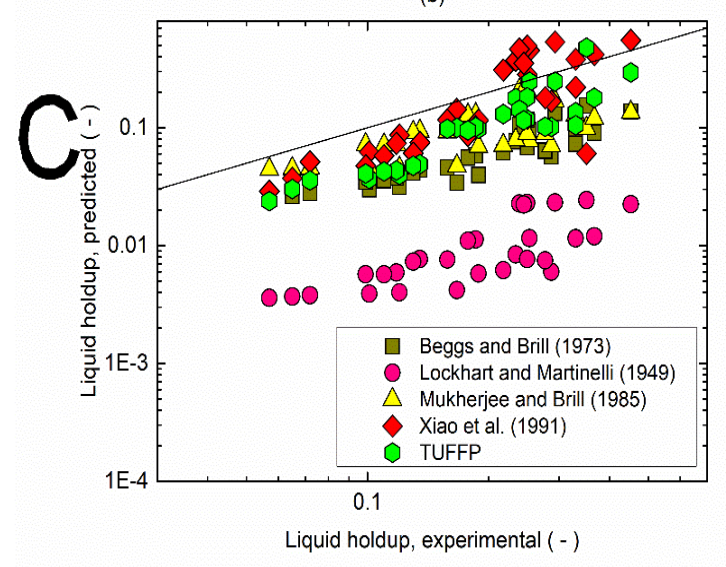

(c)

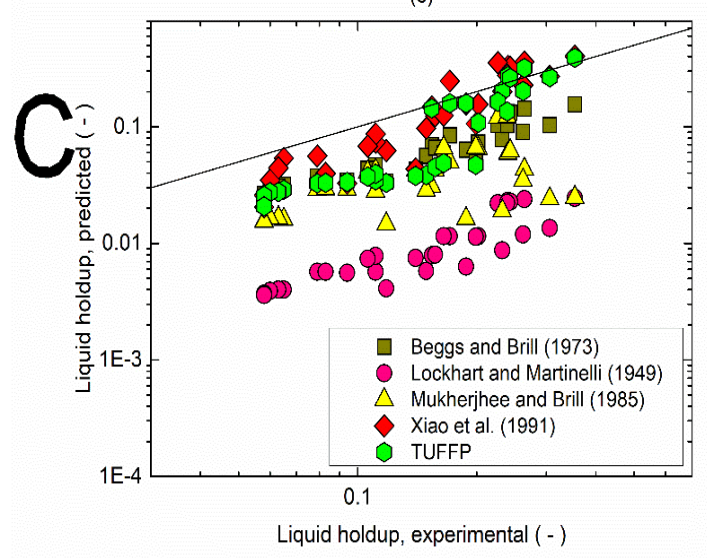

(d)

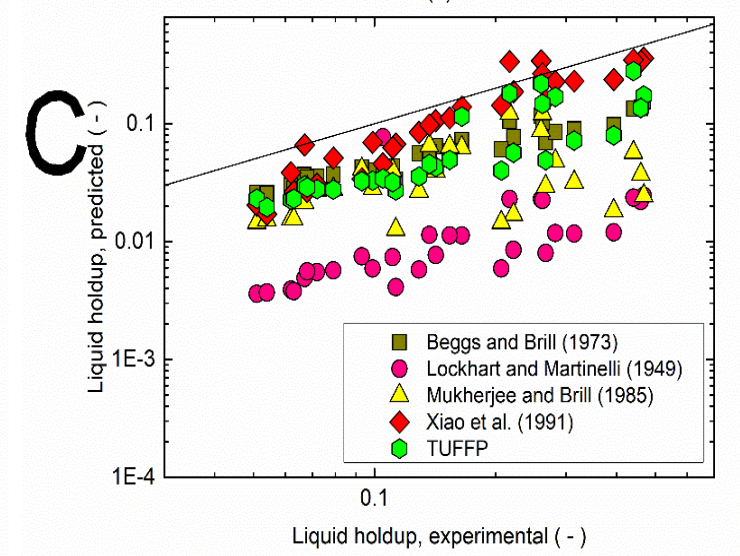

Figure 10: Comparison of liquid holdup predictions with experimental data at water-cuts of (a) $0 \%$ (b) $30 \%$ (c) $60 \%$ (d) $90 \%$ 
As will be seen in the next section, the large scatter in the different models for the prediction of liquid holdup do not significantly affect the pressure drops. It is noted that other parameters such as the friction factors, and entrained droplet fraction are at play as well as the holdup which the pressure drop in selected models (TUFFP and Beggs \& Brill) are not particularly sensitive to. Nevertheless, the predicted pressure drops compare favourably to the measured values especially at low gas Reynolds numbers.

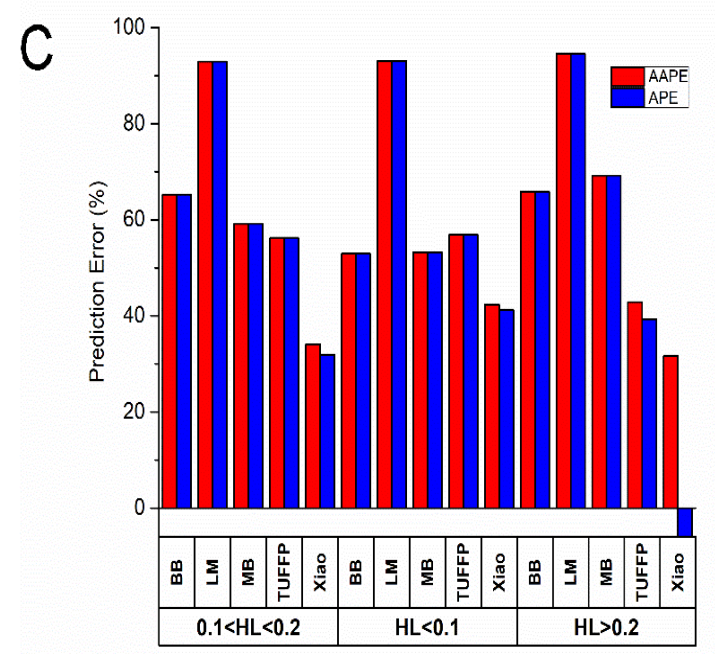

Figure 11: Results of assessment of model predictions of liquid holdup at various categories

Gas void fraction for each condition was calculated from the measured liquid holdups and was compared with the predictions of seven drift flux correlations including those of Bonnecaze et al. [72], Nicklin et al. [73], Hughmark [74], Gregory and Scott [75], Mattar and Gregory [76], Kokal and Stanislav [77] and Dix [78] as presented by Woldesemayat and Ghajar [78]. It is important to note that while most liquid holdup correlations (including those considered for this study) require flow pattern data, these drift flux correlations are flow pattern independent. Representative correlations and related conditions under which they were developed are presented in Table 4. AAPE and APE (equations 36 and 37) are the statistical parameters used to evaluate the performance of the predictions. Results of the assessment is presented in Table 5. A cross-plot of the experimental and predicted gas void fraction data using the best performing correlations is presented in Figure 12.

For the two-phase experimental data, the results show that Bonnecaze et al. [72], Nicklin et al. [73] and Kokal and Stanislav [77] present the best performance. In fact, it is found that they exhibit similar performances. The second-best performance is presented by Mattar and Gregory [76] and is followed by that of Dix [78]. It is observed that differences in fluid properties as well as pipe dimensions and 
Published in Heat and Mass Transfer, DOI: https://doi.org/10.1007/s00231-019-02616-y

configuration employed in the development of the correlations, compared to those utilized in the study, has no effect on their predictions. All correlations agree well with the experimental data and predict with comparatively low AAPE and APE values. The results assessment of the correlations with three-phase flow data indicate a better performance over that of two-phase flow. However, the performance trend exhibited by the correlations remain the same. When the two- and three-phase data are combined, the correlations still exhibit very satisfactory performances.

The performance of Bonnecaze et al. [72], Nicklin et al. [73] and Kokal and Stanislav [77] can be attributed to the utilization of a drift velocity component which accounts for pipe and fluid properties. All authors use a distribution coefficient $\left({ }^{C_{o} C_{o}}\right)$ of 1.2 which seems to work well. Mattar and Gregory [76] employs a fixed drift velocity value of 0.7 which yields good results. However, it can be inferred from results of Bonnecaze et al. [72], Nicklin et al. [73] and Kokal and Stanislav [77] that the drift velocity is a function of fluid properties and pipe diameter, the results are better. Though result of the evaluation of the predictions of Hughmark [74], Gregory and Scott [75] are satisfactory, their performances could improve with the addition of a drift velocity component. The Dix [78] correlation presents comparatively high prediction errors. This could be the result of his method to estimate the distribution coefficient. It is observed that estimation of the distribution coefficient yields values less than 1 which is lower than 1.2 utilized by the other correlations. Generally, it was found that the predictions of all the correlations can be considered satisfactory and agree well with the experimental data.

Table 4: Selected drift flux correlations for prediction of gas void fraction

\begin{tabular}{|c|c|c|}
\hline Author & Correlation & Remarks \\
\hline Bonnecaze et al. [72] & $\begin{array}{l}\varepsilon=v_{s g} /\left(1.2 v_{m}+0.35 \sqrt{g D}\left(1-\frac{\rho_{g}}{\rho_{l}}\right)\right) \\
\varepsilon=v_{s g} /\left(1.2 v_{m}+0.35 \sqrt{g D}\left(1-\frac{\rho_{g}}{\rho_{l}}\right)\right)\end{array}$ & $\begin{array}{l}\text { Inclination } \\
\text { horizontal) }\end{array} \quad\left(_{10}{ }^{\circ \circ}\right.$ from \\
\hline Nicklin et al. [73] & $\begin{array}{l}\varepsilon=v_{s g} /\left(1.2 v_{m}+0.35 \sqrt{g D}\right) \\
\varepsilon=v_{s g} /\left(1.2 v_{m}+0.35 \sqrt{g D}\right)\end{array}$ & $\begin{array}{l}\text { Pipe I.D = } 1.02 \text { in. }(0.0259 \mathrm{~m}) \text {, } \\
\text { air-water, inclination }\left(90^{\circ}\right)\end{array}$ \\
\hline Hughmark [74] & $\varepsilon=v_{s g} / 1.2 v_{m} \varepsilon=v_{s g} / 1.2 v_{m}$ & $\begin{array}{l}\text { Pipe I.D }=1.049-3.0 \text { in. } \\
(0.0264-0.0763 \text { m) air-water, } \\
\text { horizontal flow }\end{array}$ \\
\hline $\begin{array}{l}\text { Gregory and Scott } \\
{[75]}\end{array}$ & $\varepsilon=v_{s g} / 1.19 v_{m} \varepsilon=v_{s g} / 1.19 v_{m}$ & $\begin{array}{l}\text { Pipe I.D }=0.75 \text { in. }(0.01905 \mathrm{~m}) \text {, } \\
\mathrm{CO}_{2} \text {-water, horizontal flow }\end{array}$ \\
\hline
\end{tabular}


Published in Heat and Mass Transfer, DOI: https://doi.org/10.1007/s00231-019-02616-y

\begin{tabular}{|c|c|c|}
\hline $\begin{array}{l}\text { Mattar and Gregory } \\
\text { [76] }\end{array}$ & $\varepsilon=v_{s g} /\left(1.2 v_{m}+0.7\right) \varepsilon=v_{s g} /\left(1.2 v_{m}+0.7\right)$ & $\begin{array}{l}\text { Pipe I.D }=1.0 \text { in }(0.0254 \mathrm{~m}) \text {, } \\
\text { air-light oil, inclination }(0-0- \\
10 \text { from horizontal) }\end{array}$ \\
\hline $\begin{array}{l}\text { Kokal and Stanislav } \\
\text { [77] }\end{array}$ & $\begin{array}{l}\varepsilon=v_{s g} /\left(1.2 v_{m}+0.345 \sqrt{\frac{g D\left(\rho_{l}-\rho_{g}\right)}{\rho_{l}}}\right) \\
\varepsilon=v_{s g} /\left(1.2 v_{m}+0.345 \sqrt{\frac{g D\left(\rho_{l}-\rho_{g}\right)}{\rho_{l}}}\right)\end{array}$ & $\begin{array}{l}\text { Pipe I.D = 0.0258-0.0763 m, } \\
\text { air-oil, inclination (-5 to }+9{ }^{\circ} \\
{ }^{\circ}\end{array}$ \\
\hline Dix [78] & $\begin{array}{l}\varepsilon=v_{s g}\left[v_{s g}\left(1+\left(\frac{v_{s l}}{v_{s g}}\right)^{\left(\frac{\rho_{g}}{\rho_{l}}\right)^{0.1}}\right)+2.9\left(\frac{g \sigma\left[\rho_{l}-\rho_{g}\right]}{\rho_{l}^{2}}\right)^{0.25}\right]^{-1} \\
\varepsilon=v_{s g}\left[v_{s g}\left(1+\left(\frac{v_{s l}}{v_{s g}}\right)^{\left(\frac{\rho_{g}}{\rho_{l}}\right)^{0.1}}\right)+2.9\left(\frac{g \sigma\left[\rho_{l}-\rho_{g}\right]}{\rho_{l}^{2}}\right)^{0.25}\right]^{-1}\end{array}$ & $\begin{array}{l}\text { Data obtained using rod } \\
\text { bundles, subcooled boiled } \\
\text { conditions }\end{array}$ \\
\hline
\end{tabular}

Table 5: Predictions of selected drift flux correlations for experimental data

\begin{tabular}{lllllllll}
\hline WC & Stats & $\begin{array}{c}\text { Bonnecaze } \\
\text { et al. [72] }\end{array}$ & $\begin{array}{c}\text { Nicklin et } \\
\text { al. [73] }\end{array}$ & $\begin{array}{c}\text { Hughmark } \\
\text { [74] }\end{array}$ & $\begin{array}{c}\text { Gregory } \\
\text { and Scott } \\
{[75]}\end{array}$ & $\begin{array}{c}\text { Mattar and } \\
\text { Gregory [76] }\end{array}$ & $\begin{array}{c}\text { Kokal and } \\
\text { Stanislav } \\
\text { [77] }\end{array}$ & Dix [78] \\
\hline $0 \%$ & AAPE & 13.5484 & 13.5466 & 16.4679 & 16.5599 & 14.188 & 13.5844 & 21.6544 \\
& APE & -3.1258 & -3.1226 & -7.8404 & -8.7466 & 9.1397 & -3.1885 & -21.6544 \\
$30 \%$ & AAPE & 8.1518 & 8.15 & 11.3246 & 11.6212 & 11.9638 & 8.1892 & 19.5239 \\
& APE & -1.6197 & -1.6168 & -6.0749 & -6.9663 & 10.2887 & -1.6789 & -19.5239 \\
$60 \%$ & AAPE & 6.4383 & 6.4383 & 7.8854 & 7.8109 & 15.7691 & 6.4383 & 11.9087 \\
& APE & 4.6035 & 4.606 & 0.4179 & -0.4189 & 15.7691 & 4.548 & -11.9087 \\
$90 \%$ & AAPE & 11.2829 & 11.2821 & 13.8257 & 13.7738 & 14.124 & 11.3012 & 16.3806 \\
& APE & 0.4013 & 0.4039 & -4.2394 & -5.1154 & 12.2794 & 0.34 & -16.3806 \\
\multirow{2}{*}{ Overall } & AAPE & 9.8554 & 9.8543 & 12.3759 & 12.4415 & 14.0112 & 9.8782 & 17.3669 \\
& APE & 0.0648 & 0.0676 & -4.4342 & -5.3118 & 11.8692 & 0.0052 & -17.3669 \\
\hline
\end{tabular}




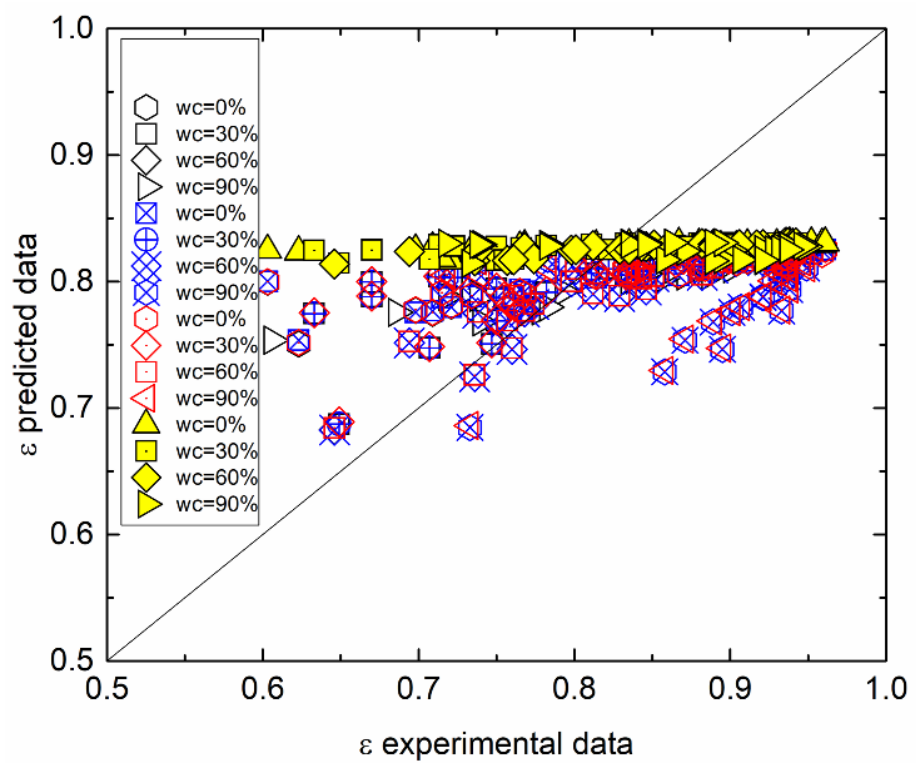

Figure 12: Comparison of predictions of Bonnecaze et al. [72] (black), Nicklin et al. [73] (blue), Kokal and Stanislav [77] (red) and Hughmark [74] (yellow) with the present experimental gas void fraction data

\subsubsection{Pressure Drop}

Figure 13 presents a cross-plot of the experimental and predictions of the selected models at various water-cuts. The performance of model predictions was evaluated using statistical parameters AAPE and APE (Eq. 42 and 43).

For two-phase flows ( $0 \%$ water-cut), it is found that the Xiao et al model [23] exhibits the best performance (APPE=42.63, APE=-4.02). The model employs a two-fluid approach which integrates the roles of shear stresses and friction factors in the prediction of pressure gradient for both stratified (Eq. 29) and annular (Eq. 34) flow regimes. The adoption of the Taitel and Dukler (1976) model for stratified flow seems to work well. However, perhaps the performance of the model could still improve if more efficient closure relationships were employed. For instance, the authors reported major uncertainties with the interfacial friction factor in stratified flow and recommended further studies to identify more accurate predictive correlations. Further, for annular flow, both correlations for liquid entrainment and interfacial friction factor adopted were derived from annular flow experiments, results from which may not be accurate for horizontal flow conditions. Also, a large percentage of the data used for the development of the model was obtained using small diameter pipes. This could be negatively influencing accuracy of its prediction since data obtained using comparatively larger pipe diameters were used for this study. Karami et al. [14] also reported a good performance by this model during a similar experimental study. Though the TUFFP model employs a two-fluid approach, its performance is not as 
expected (APPE=186.73, APE=-186.73). The simplification of the stratified and annular flow regimes into one regime could be posing challenges to efficient pressure gradient prediction. In addition, the TUFFP model [24] develops correlations for the various flow regimes via slug flow. The same basic equations are used to predict the flow pattern, pressure gradient, liquid holdup and other flow behaviours [79]. Selection of closure relationships (for instance, wettability, interfacial friction factor and wall friction factors), may not be consistent with the hydrodynamic models used as highlighted by the authors [24] has been recently demonstrated by Karami et al. [80]. The performance of the Beggs and Brill model [19] is also not as expected (AAPE=131.98) with high over-prediction (APE=-131.98). Similarly, overprediction of the Beggs and Brill model was observed by Karami et al. [14] in their three-phase flow studies. This could be emanating from the limitations of the empirical nature of the model. Under low liquid loading conditions large slip occurring between the gas and liquid phases due to large velocity differences is not accounted for. Again, the model does not account for present shear stresses which occur. On the other hand, it employs a Blasius-type friction factor applicable to single-phase flows. For the calculation of the frictional pressure drop, the model employs no-slip conditions in the two-phase friction factor calculation as well as the density which fails to describe to phenomenon in the flow regime. Additionally, the Beggs and Brill model was developed based on data obtained using air-water mixtures and smaller pipes. These conditions differ from what was obtained for the study. These, combined with its difficulty to satisfactorily predict the flow pattern could be influencing the low prediction performance observed.

(a)

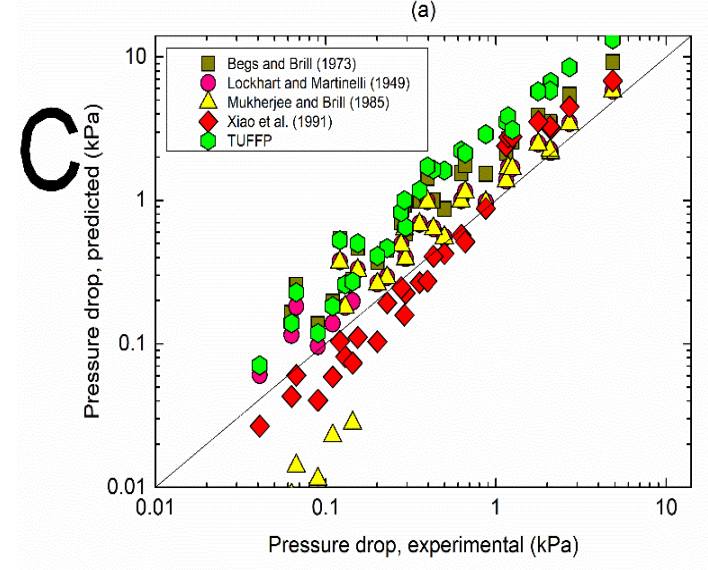

(b)

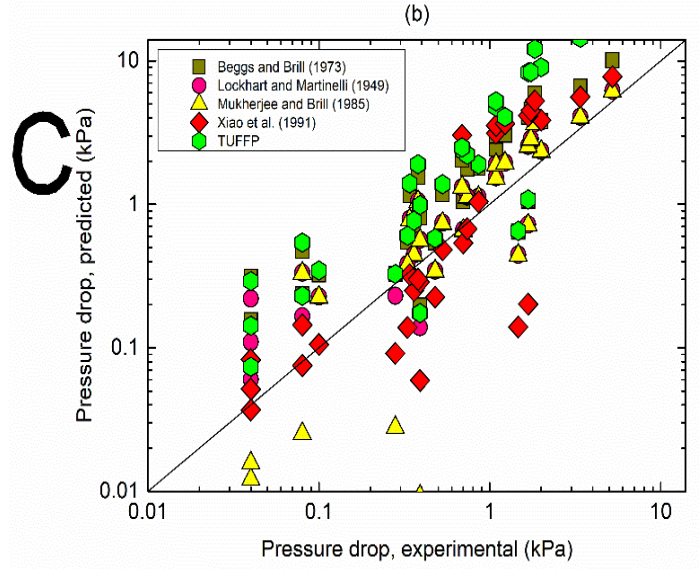


(c)

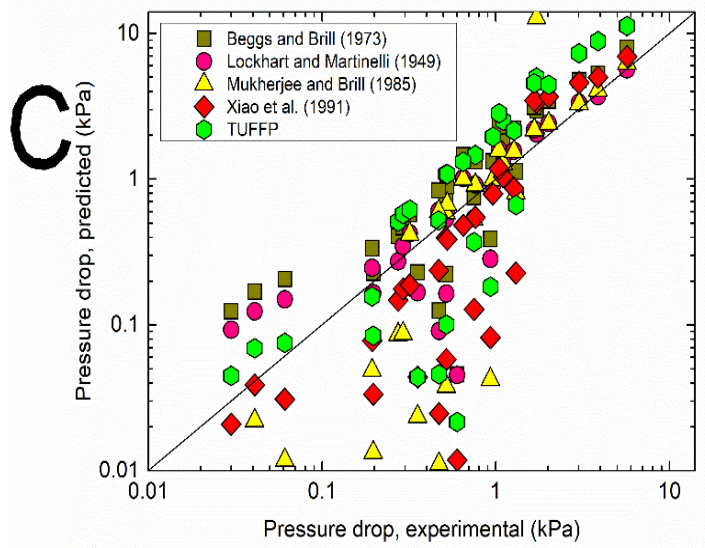

(d)

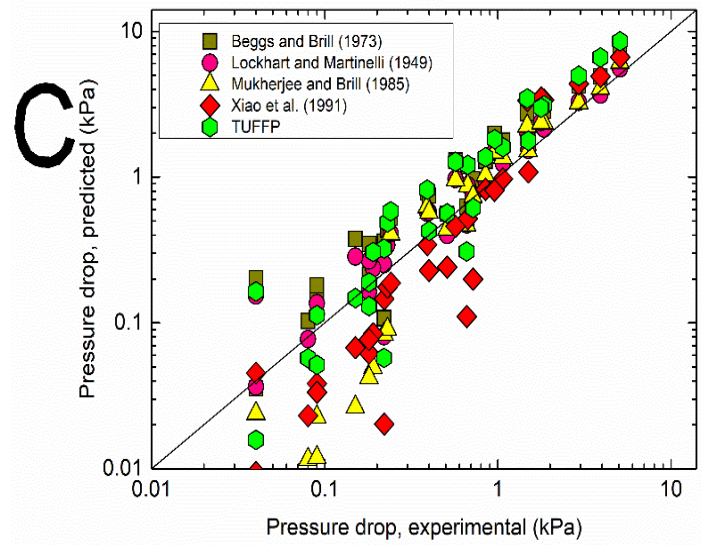

Figure 13: Comparison of pressure drop prediction for (a) $0 \%$ (b) $30 \%$ (c) $60 \%$ and (d) $90 \%$ water-cuts

Though the TUFFP model employs a two-fluid approach, its performance is not as expected (APPE=186.73, APE=-186.73). The simplification of the stratified and annular flow regimes into one regime could be posing challenges to efficient pressure gradient prediction. In addition, the TUFFP model [24] develops correlations for the various flow regimes via slug flow. The same basic equations are used to predict the flow pattern, pressure gradient, liquid holdup and other flow behaviours [79]. Selection of closure relationships (for instance, wettability, interfacial friction factor and wall friction factors), may not be consistent with the hydrodynamic models used as highlighted by the authors [24] has been recently demonstrated by Karami et al. [80]. The performance of the Beggs and Brill model [19] is also not as expected (AAPE=131.98) with high over-prediction (APE=-131.98). Similarly, overprediction of the Beggs and Brill model was observed by Karami et al. [14] in their three-phase flow studies. This could be emanating from the limitations of the empirical nature of the model. Under low liquid loading conditions large slip occurring between the gas and liquid phases due to large velocity differences is not accounted for. Again, the model does not account for present shear stresses which occur. On the other hand, it employs a Blasius-type friction factor applicable to single-phase flows. For the calculation of the frictional pressure drop, the model employs no-slip conditions in the two-phase friction factor calculation as well as the density which fails to describe to phenomenon in the flow regime. Additionally, the Beggs and Brill model was developed based on data obtained using air-water mixtures and smaller pipes. These conditions differ from what was obtained for the study. These, combined with its difficulty to satisfactorily predict the flow pattern could be influencing the low prediction performance observed. Estimation of the total pressure gradient using the Lockhart and Martinelli model requires determination of dimensionless pressure parameters (functions of fluid properties and the phase flow rates). Though the model is flow regime independent, it attempts to capture the physical behaviour of the liquid and 
Published in Heat and Mass Transfer, DOI: https://doi.org/10.1007/s00231-019-02616-y

gas phases using the liquid and gas Reynolds numbers. Further, utilisation of data obtained by using liquid of varied viscosities provide an inherent ability to manage fluctuations in liquid viscosities, a property which is observed when it is evaluated using three-phase flow data. These, perhaps, provide reasons for its satisfactory performance. It appears, however, that sole use of the Reynolds number is inadequate to fully describe the dynamics of the flow. Identification and application of other dimensionless numbers for this purpose could improve predictions significantly. The performance of the Mukherjee and Brill model is satisfactory (AAPE=60.33). For pressure gradient prediction, the model employs a two-fluid model for stratified flow and an empirical model for annular flow. Considering the potential limitations posed by the empirical correlation, it is possible the observed performance of the model is derived from predictions of the stratified flow data which is dominant.

It has been shown that the three-phase flow systems exhibit similar characteristics akin to two the two-phase flow systems (sections 3.1- 3.4). For this experimental data, it is found that models' predictions are also reasonable for three-phase flow systems (Figure 13b-d). It is surprising, however, to observed that the performance of all models improves as water content increases. As water-cut increases, water gradually becomes the continuous medium and the gas-liquid mixture tends to become more like an air-water two-phase flow system. At 90\% water-cut, water becomes the continuous liquid phase mimicking the liquid properties used for correlation development or validation. At 30\% water-cut, both the Beggs and Brill [19] and TUFFP models present errors of more than 100\%. For the Beggs and Brill model, this can be attributed to the differences in liquid viscosity and the related shear stress it does not account for. The prediction errors of the rest fall below $85 \%$ with the lowest offered by the Mukherjee and Brill model (AAPE=70.24). At water-cut of $60 \%$, however, the Lockhart and Martinelli model exhibits the best performance (AAPE=46.76) followed by the Xiao et al. model (AAPE=52.91). All models exhibit their best performance at water-cut of $90 \%$. As suggested, this could be attributed to favourable liquid properties. It is also observed that the Mukherjee and Brill model [21] exhibits similar performances with the Xiao et al. [23] model at 90\% water-cut.

When model predictions are assessed over the entire data (two- and three-phase flows), it is observed that the Lockhart and Martinelli [20], Mukherjee and Brill [21] as well as the Xiao et al [23] models have relative low prediction errors ( $A A P E=54.09,61.93,56.71$ respectively). In addition, it is observed that overpredict the data. The Xiao et al [23] offers the least overprediction (APE=-0.28). 
Published in Heat and Mass Transfer, DOI: https://doi.org/10.1007/s00231-019-02616-y

\section{Conclusions}

An experimental study has been conducted using air and oil as well as gas and homogeneously mixed oil and water at different water-cuts at low liquid conditions with the view to evaluate predicted target flow characteristics (flow pattern, liquid holdup and pressure gradient) of selected existing models. The following salient conclusions can be made from the study. Stratified smooth, stratified-wavy and stratified-annular flow patterns were observed during the experiment. 2D, 3D and roll waves were observed as superficial gas velocity increased. Water-cut affected the flow pattern, shifting the transition boundary between stratified-wavy and stratified-annular to the left, towards lower gas superficial velocities. The influence of water-cut on pressure drop and liquid holdup, however, was found to be negligible. With regard to flow pattern prediction, the Xiao et al [23] model exhibits an outstanding and consistent agreement with our experiments for all water-cuts and over the entire set of data points. The performance of the other models fluctuates at different water-cuts. This could be because they were developed with data from a myriad of sources which do not necessarily account for water-cut. Their performance over the entire database is not satisfactory. The Xiao et al. (1990) model demonstrates a better performance when the accuracy of models is evaluated for liquid holdup prediction. The model presents predictions with comparatively low error. The TUFFP model exhibits the second-best performance. The prediction errors of the Lockhart and Martinelli model are relatively high, possibly because it was developed to be flow regime independent, where there is little interfacial slip between the gas and liquid phases. When the models are assessed based on the liquid holdup values it is found that the Xiao et al. (1990) model has the best performance in all categories. Generally, the Lockhart and Martinelli, Mukherjee and Brill as well as the Xiao et al models predict the pressure drop data with acceptable accuracies for the air-water-oil flows studied. The performance of the Lockhart and Martinelli correlation is attributable to its ability to capture flow conditions and also inherent manage fluctuations in liquid viscosities. The performance of the Mukherjee and Brill can be attributed to the efficiency of the two-fluid model employed for the stratified flow data. The efficiency of the Xiao et al. model is attributable to its ability to capture the flow dynamics in the stratified and annular flow regimes.

\section{Nomenclature}

$\theta \Theta$ wetted wall fraction [-]

$\theta_{0} \theta_{0}$ minimum wetted wall fraction [-] 


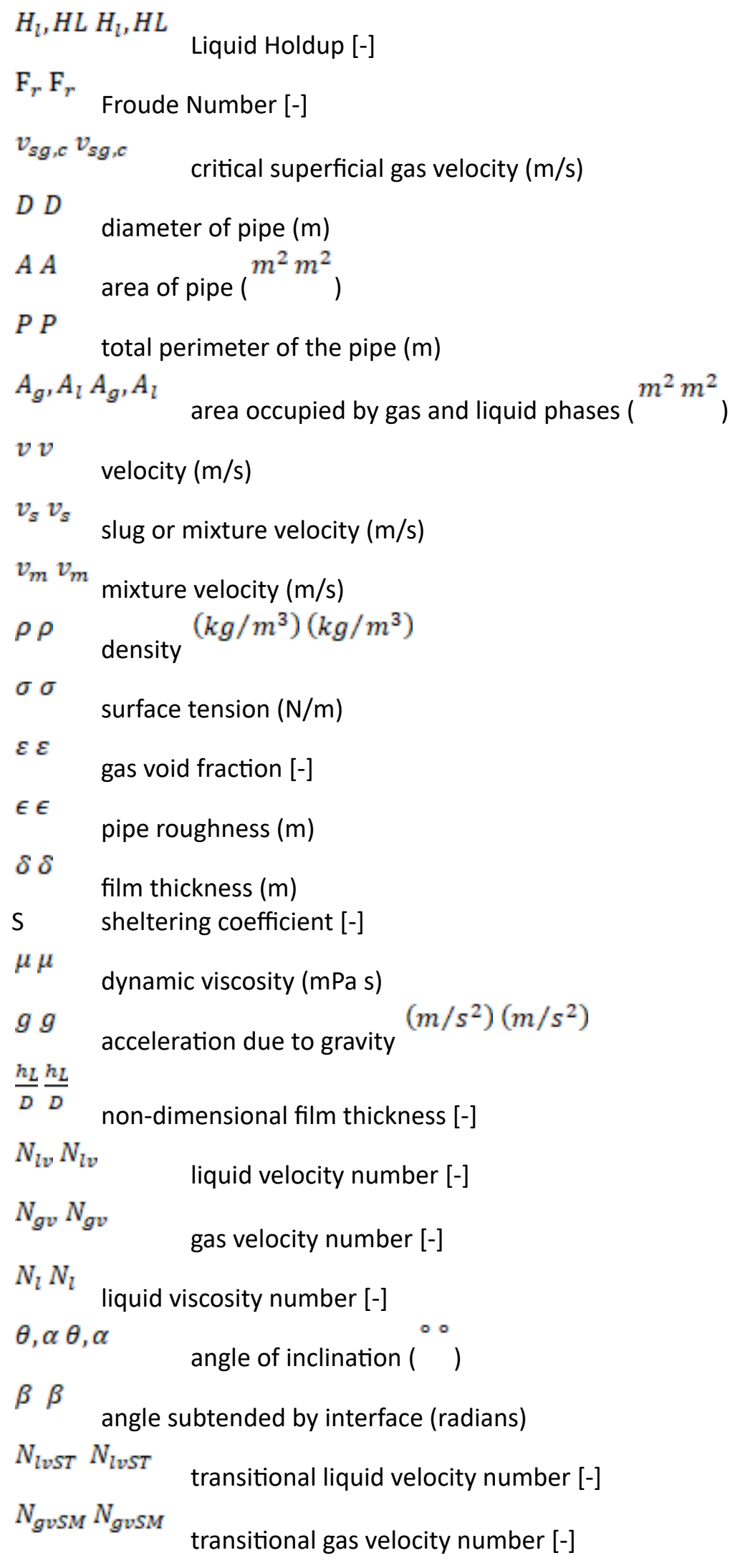




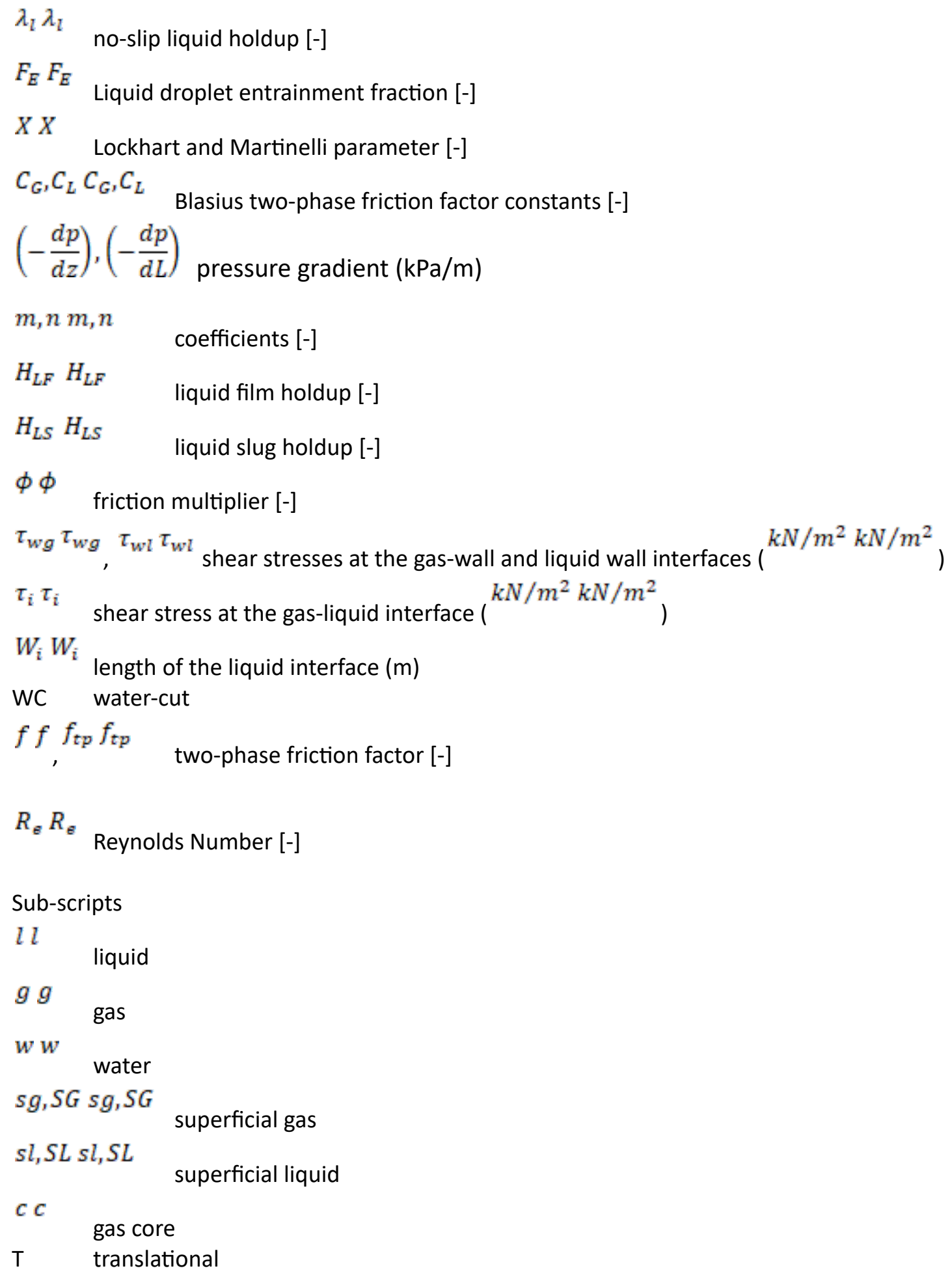

\section{ACKNOWLEDGEMENT}

This work was supported by the National Science and Technology Major Project of the Ministry of Science and Technology of China (2017ZX05030-003-005). 
Published in Heat and Mass Transfer, DOI: https://doi.org/10.1007/s00231-019-02616-y

\section{CONFLICT OF INTEREST}

The authors declare that they have no conflict of interest.

\section{References}

1. Meng W, Chen XT, Kouba GE, et al (2001) Experimental Study of Low-Liquid-Loading Gas-Liquid Flow in Near-Horizontal Pipes. SPE Prod Facil 16:240-249. https://doi.org/10.2118/74687-PA

2. Banafi A, Talaei MR, Ghafoori MJ (2014) A comprehensive comparison of the performance of several popular models to predict pressure drop in stratified gas-liquid flow with low liquid loading. J Nat Gas Sci Eng 21:433-441. https://doi.org/10.1016/j.jngse.2014.09.009

3. $\quad \mathrm{Ng}$ TS, Lawrence CJ, Hewitt GF (2002) Laminar stratified pipe flow. Int J Multiph Flow 28:963-996. https://doi.org/10.1016/S0301-9322(02)00004-6

4. Kesana NR, Ibarra R, Langsholt $M$, et al (2018) Measurements of local droplet velocities in horizontal gas-liquid pipe flow with low liquid loading. J Pet Sci Eng 170:184-196. https://doi.org/10.1016/j.petrol.2018.06.019

5. Vuong DH, Sarica C, Pereyra E, Al-Sarkhi A (2017) Liquid droplet entrainment in two-phase oil-gas low-liquid-loading flow in horizontal pipes at high pressure. Int J Multiph Flow 99:383-396. https://doi.org/10.1016/j.ijmultiphaseflow.2017.11.007

6. Skartlien R, Nuland S, Amundsen JE (2011) Simultaneous entrainment of oil and water droplets in high Reynolds number gas turbulence in horizontal pipe flow. Int J Multiph Flow 37:1282-1293. https://doi.org/10.1016/j.ijmultiphaseflow.2011.07.006

7. Kesana NR, Skartlien R, Langsholt M, et al (2018) Droplet flux measurements in two-phase, low liquid loading, horizontal pipe flow using a high-density gas. J Nat Gas Sci Eng 56:472-485. https://doi.org/10.1016/j.jngse.2018.06.004

8. Xu XX (2007) Study on oil-water two-phase flow in horizontal pipelines. J Pet Sci Eng 59:43-58. https://doi.org/10.1016/j.petrol.2007.03.002

9. Keskin C, Zhang H, Sarica C (2007) Identification and Classification of New Three-Phase Gas/Oil/Water Flow Patterns. In: SPE Annual Technical Conference and Exhibition. Society of Petroleum Engineers, pp 1-13

10. Al-Hadhrami LM, Shaahid SM, Tunde LO, Al-Sarkhi A (2014) Experimental Study on the Flow Regimes and Pressure Gradients of Air-Oil-Water Three-Phase Flow in Horizontal Pipes. Sci World J 2014:1-11. https://doi.org/10.1155/2014/810527

11. Hewitt GF (2006) MULTIPHASE FLOW. In: A-to-Z Guide to Thermodynamics, Heat and Mass Transfer, and Fluids Engineering. Begellhouse

12. Shmueli A, Unander TE, Nydal OJ (2015) Characteristics of Gas/Water/Viscous Oil in Stratified-Annular Horizontal Pipe Flows. In: OTC Brasil. Offshore Technology Conference, pp 1-18

13. Wang K, Bai B, Ma W (2013) Huge wave and drop entrainment mechanism in gas-liquid churn flow. Chem Eng Sci 104:638-646. https://doi.org/10.1016/j.ces.2013.09.022

14. Karami H, Torres CF, Pereyra E, Sarica C (2015) Experimental Investigation of Three-Phase Low 
Published in Heat and Mass Transfer, DOI: https://doi.org/10.1007/s00231-019-02616-y

Liquid Loading Flow. In: SPE Annual Technical Conference and Exhibition. Society of Petroleum Engineers, pp 28-30

15. Hewitt GF (2005) Three-phase gas-liquid-liquid flows in the steady and transient states. Nucl Eng Des 235:1303-1316. https://doi.org/10.1016/j.nucengdes.2005.02.023

16. Bonizzi M, Issa RI (2003) On the simulation of three-phase slug flow in nearly horizontal pipes using the multi-fluid model. Int J Multiph Flow 29:1719-1747. https://doi.org/10.1016/j.ijmultiphaseflow.2003.09.002

17. Zhang H, Sarica C (2006) Unified Modeling of Gas/Oil/Water Pipe Flow - Basic Approaches and Preliminary Validation. SPE Proj Facil Constr 1:1-7. https://doi.org/10.2118/95749-PA

18. Zhang HQ, Sarica C (2011) Low liquid loading gas/liquid pipe flow. J Nat Gas Sci Eng 3:413-422. https://doi.org/10.1016/j.jngse.2011.03.001

19. Beggs, D.H., Brill JP (1973) A Study of Two-Phase Flow in Inclined Pipes. J. Pet. Technol. 25:607-617

20. Shoham O (2005) Mechanistic Modeling of gas liquid two phase flow in pipes. 240-250

21. Mukherjee H, Brill JP (1985) Pressure Drop Correlations for Inclined Two-Phase Flow. J Energy Resour Technol 107:549. https://doi.org/10.1115/1.3231233

22. Mukherjee H, Brill JP (1983) Liquid Holdup Correlations for Inclined Two-Phase Flow. J Pet Technol 35:1003-1008. https://doi.org/10.2118/10923-PA

23. Xiao JJ, Shonham O, Brill JP (1990) A Comprehensive Mechanistic Model for Two-Phase Flow in Pipelines. In: SPE Annual Technical Conference and Exhibition. Society of Petroleum Engineers, pp 167-180

24. Zhang H-Q, Wang Q, Sarica C, Brill JP (2003) Unified Model for Gas-Liquid Pipe Flow via Slug Dynamics-Part 1: Model Development. J Energy Resour Technol 125:266. https://doi.org/10.1115/1.1615246

25. Bugg JD, Saad GA (2002) The velocity field around a Taylor bubble rising in a stagnant viscous fluid: Numerical and experimental results. Int J Multiph Flow 28:791-803. https://doi.org/10.1016/S0301-9322(02)00002-2

26. Ayati AA, Kolaas J, Jensen A, Johnson GW (2014) A PIV investigation of stratified gas-liquid flow in a horizontal pipe. Int J Multiph Flow 61:129-143. https://doi.org/10.1016/j.ijmultiphaseflow.2014.01.008

27. Ayati AA, Kolaas J, Jensen A, Johnson GW (2015) Combined simultaneous two-phase PIV and interface elevation measurements in stratified gas/liquid pipe flow. Int J Multiph Flow 74:45-58. https://doi.org/10.1016/j.ijmultiphaseflow.2015.03.024

28. Ayati AA, Kolaas J, Jensen A, Johnson GW (2016) The effect of interfacial waves on the turbulence structure of stratified air/water pipe flow. Int J Multiph Flow 78:104-116. https://doi.org/10.1016/j.ijmultiphaseflow.2015.09.007

29. Birvalski M, Tummers MJ, Henkes RAWM (2016) Measurements of gravity and gravity-capillary waves in horizontal gas-liquid pipe flow using PIV in both phases. Int J Multiph Flow 87:102-113. https://doi.org/10.1016/j.ijmultiphaseflow.2016.09.003 
Published in Heat and Mass Transfer, DOI: https://doi.org/10.1007/s00231-019-02616-y

30. Morgan RG, Ibarra R, Zadrazil I, et al (2017) On the role of buoyancy-driven instabilities in horizontal liquid-liquid flow. Int J Multiph Flow 89:123-135. https://doi.org/10.1016/j.ijmultiphaseflow.2016.07.009

31. Zhou Y (2017) Rayleigh-Taylor and Richtmyer-Meshkov instability induced flow, turbulence, and mixing. I. Phys Rep 720-722:1-136. https://doi.org/10.1016/j.physrep.2017.07.005

32. Vaze MJ, Banerjee J (2012) Estimation of Wall Shear Stress in Two-Phase Flow Using Hot Film Anemometry. Int Conf Fluid Dyn Thermodyn Technol 33:58-63

33. Vlachos NA, Paras S V., Karabelas AJ (1999) Prediction of holdup, axial pressure gradient and wall shear stress in wavy stratified and stratified/atomization gas/liquid flow. Int J Multiph Flow 25:365-376. https://doi.org/10.1016/S0301-9322(98)00049-4

34. Birvalski M, Henkes R (2012) Experiments and modelling of multiple holdup states for gas/liquid flow in a pipeline. 8th North Am Conf Multiph Technol 289-304

35. Nädler M, Mewes D (1995) Intermittent Three-Phase Flow of Oil Water And Gas In Horizontal Pipes. Fifth Int Offshore Polar Eng Conf II:72-80

36. Gokcal B, Wang Q, Zhang H-Q, Sarica C (2008) Effects of High Oil Viscosity on Oil/Gas Flow Behavior in Horizontal Pipes. SPE Proj Facil Constr 3:1-11. https://doi.org/10.2118/102727-PA

37. Farsetti $S$, Farisè $S$, Poesio $P$ (2014) Experimental investigation of high viscosity oil-air intermittent flow. Exp Therm Fluid Sci 57:. https://doi.org/10.1016/j.expthermflusci.2013.12.004

38. Poesio P, Strazza D, Sotgia G (2012) Two- and three-phase mixtures of highly-viscous-oil/water/air in a $50 \mathrm{~mm}$ i.d. pipe. Appl Therm Eng 49:41-47. https://doi.org/10.1016/j.applthermaleng.2011.04.052

39. Picchi D, Poesio P, Ullmann A, Brauner N (2017) Characteristics of stratified flows of Newtonian/non-Newtonian shear-thinning fluids. Int J Multiph Flow 97:109-133. https://doi.org/10.1016/j.ijmultiphaseflow.2017.06.005

40. Taitel Y, Barnea D, Brill JP (1995) Stratified three phase flow in pipes. Int J Multiph Flow 21:53-60. https://doi.org/10.1016/0301-9322(94)00058-R

41. Oddie G, Shi H, Durlofsky LJ, et al (2003) Experimental study of two and three phase flows in large diameter inclined pipes. Int J Multiph Flow 29:527-558. https://doi.org/10.1016/S0301-9322(03)00015-6

42. Herm Stapelberg H, Mewes D (1994) The pressure loss and slug frequency of liquid-liquid-gas slug flow in horizontal pipes. Int J Multiph Flow 20:285-303. https://doi.org/10.1016/0301-9322(94)90083-3

43. Poesio P, Strazza D, Sotgia G (2009) Very-viscous-oil/water/air flow through horizontal pipes: Pressure drop measurement and prediction. Chem Eng Sci 64:1136-1142. https://doi.org/10.1016/j.ces.2008.10.061

44. Chen X, Guo L (1999) Flow patterns and pressure drop in oil-air-water three-phase flow through helically coiled tubes. Int J Multiph Flow 25:1053-1072. https://doi.org/10.1016/S0301-9322(99)00065-8

45. Fan $\mathrm{Y}$, Wang Q, Zhang $\mathrm{H}-\mathrm{Q}$, et al (2007) A Model To Predict Liquid Holdup and Pressure Gradient 
Published in Heat and Mass Transfer, DOI: https://doi.org/10.1007/s00231-019-02616-y

of Near-Horizontal Wet-Gas Pipelines. SPE Proj Facil Constr 2:1-8. https://doi.org/10.2118/95674-PA

46. Parsi M, Vieira RE, Torres CF, et al (2015) On the effect of liquid viscosity on interfacial structures within churn flow: Experimental study using wire mesh sensor. Chem Eng Sci 130:221-238. https://doi.org/10.1016/j.ces.2015.03.033

47. Dong H, Zhang H., Sarica C (2009) An experimental study of low liquid loading gas-oil-water flow in horizontal pipes. Multiph Prod Technol 17-27

48. Gawas K (2013) Studies in low-liquid loading in gas/oil/water three phase flow in horizontal and near-horizontal pipes. University of Tulsa, Tulsa, OK

49. Karami H, Pereyra E, Torres C, Sarica C (2017) Droplet entrainment analysis of three-phase low liquid loading flow. Int J Multiph Flow 89:45-56. https://doi.org/http://dx.doi.org/10.1016/j.ijmultiphaseflow.2016.10.011

50. Taitel Y, Dukler AE (1976) A theoretical approach to the Lockhart-Martinelli correlation for stratified flow. Int J Multiph Flow 2:591-595. https://doi.org/10.1016/0301-9322(76)90019-7

51. Andritsos N (1986) Effect of Pipe Diameter and Liquid Viscosity on Horizontal Stratified Flow. University of Illinois, Urbana

52. Grolman E, Fortuin JMH (1997) Gas-liquid flow in slightly inclined pipes. Chem Eng Sci 52:4461-4471. https://doi.org/10.1016/S0009-2509(97)00291-1

53. Oliemans RVA, Pots BFM, Trompé N (1986) Modelling of annular dispersed two-phase flow in vertical pipes. Int J Multiph Flow 12:711-732. https://doi.org/10.1016/0301-9322(86)90047-9

54. Malhotra A (1995) Study of two and three-phase flows in large diameter horizontal pipelines. Ohio University

55. Sobocinski DP (1955) Horizontal Co-Current Flow of Water, Gas- Oil and Air. University of Oklahoma, Norman, OK

56. Mandhane JM, Gregory GA, Aziz K (1974) A flow pattern map for gas-liquid flow in horizontal pipes. Int J Multiph Flow 1:537-553. https://doi.org/10.1016/0301-9322(74)90006-8

57. Açikgöz M, França F, Lahey RT (1992) An experimental study of three-phase flow regimes. Int J Multiph Flow 18:327-336. https://doi.org/10.1016/0301-9322(92)90020-H

58. Trallero JL (1995) Oil - Water Flow Patterns in Horizontal Pipes. The University of Tulsa, Tulsa, OK

59. Bannwart AC, Rodriguez $\mathrm{OMH}$, Trevisan FE, et al (2009) Experimental investigation on liquid-liquid-gas flow: Flow patterns and pressure-gradient. J Pet Sci Eng 65:1-13. https://doi.org/10.1016/j.petrol.2008.12.014

60. Huang S, Zhang B, Lu J, Wang D (2013) Study on flow pattern maps in hilly-terrain air-water-oil three-phase flows. Exp Therm Fluid Sci 47:158-171. https://doi.org/10.1016/j.expthermflusci.2013.01.011

61. Spedding PL, Spence DR (1993) Flow regimes in two-phase gas-liquid flow. Int J Multiph Flow 19:245-280. https://doi.org/10.1016/0301-9322(93)90002-C

62. Chen XT, Brill JP (1997) Slug to churn transition in upward vertical two-phase flow. Chem Eng Sci 
Published in Heat and Mass Transfer, DOI: https://doi.org/10.1007/s00231-019-02616-y

52:4269-4272. https://doi.org/10.1016/S0009-2509(97)00178-4

63. Andritsos N, Hanratty TJ (1987) Interfacial instabilities for horizontal gas-liquid flows in pipelines. Int J Multiph Flow 13:583-603. https://doi.org/10.1016/0301-9322(87)90037-1

64. Mori K, Yoshida H, Nakano K, Shiomi Y (2007) Effects of liquid viscosity on inception of disturbance waves and droplets in gas-liquid annular two-phase flow. Heat Transf - Asian Res 36:529-541. https://doi.org/10.1002/htj.20176

65. Schlumberger (2003) PIPESIM Suite, User Guide

66. Brinkman HC (1952) The Viscosity of Concentrated Suspensions and Solutions. J Chem Phys 20:571-571. https://doi.org/10.1063/1.1700493

67. Einstein A (1906) Eine Neue Bestuimmung Der Molekulardimensionen. Ann Phys (N Y) 9:289-306

68. Brauner N (1998) Liquid-liquid two-phase flow. In: HEDU - Heat Exchanger Design Update, (Chapter 2.3.5). pp 1-40

69. Becher P (2001) becher2001.pdf. In: Emulsions: theory and practice, Third. American Chemical Society, Washington, D.C, pp 65-118

70. Guet S, Rodriguez OMH, Oliemans RVA, Brauner N (2006) An inverse dispersed multiphase flow model for liquid production rate determination. Int J Multiph Flow 32:553-567. https://doi.org/10.1016/j.ijmultiphaseflow.2006.01.008

71. Brauner N, Ullmann A (2002) Modeling of phase inversion phenomenon in two-phase pipe flows. Int J Multiph Flow 28:1177-1204. https://doi.org/10.1016/S0301-9322(02)00017-4

72. Bonnecaze RH, Erskine W, Greskovich EJ (1971) Holdup and pressure drop for two-phase slug flow in inclined pipelines. AIChE J 17:1109-1113. https://doi.org/10.1002/aic.690170516

73. Nicklin D, Wilkes J, Davidson J (1962) Two-phase flow in vertical tubes. Trans Am Inst Chem Eng 40:61-68

74. Hughmark GA (1965) Holdup and heat transfer in horizontal slug gas-liquid flow. Chem Eng Sci 20:1007-1010. https://doi.org/10.1016/0009-2509(65)80101-4

75. Gregory GA, Scott DS (1969) Correlation of liquid slug velocity and frequency in horizontal cocurrent gas-liquid slug flow. AIChE J 15:933-935. https://doi.org/10.1002/aic.690150623

76. Mattar L, Gregory GA (1974) Air-Oil Slug Flow In an Upward-Inclined Pipe - I: Slug Velocity, Holdup And Pressure Gradient. J Can Pet Technol 13:69-76. https://doi.org/10.2118/74-01-07

77. Kokal SL, Stanislav J. (1989) An experimental study of two-phase flow in slightly inclined pipes-II. Liquid holdup and pressure drop. Chem Eng Sci 44:681-693. https://doi.org/10.1016/0009-2509(89)85043-2

78. Woldesemayat MA, Ghajar AJ (2007) Comparison of void fraction correlations for different flow patterns in horizontal and upward inclined pipes. Int J Multiph Flow 33:347-370. https://doi.org/10.1016/j.ijmultiphaseflow.2006.09.004

79. Akhiyarov DT, Zhang H-Q, Sarica C (2010) High-Viscosity Oil-Gas Flow in Vertical Pipe. In: Offshore Technology Conference. Offshore Technology Conference, pp 3-6

80. Karami H, Pereyra E, Sarica C (2017) Effects of monoethylene glycol (MEG) on three-phase flow 
Published in Heat and Mass Transfer, DOI: https://doi.org/10.1007/s00231-019-02616-y

characteristics in near-horizontal pipes. J Pet Sci Eng 149:834-843. https://doi.org/10.1016/j.petrol.2016.11.010 